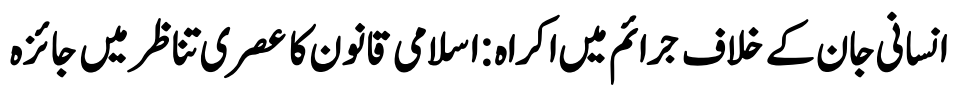

\section{Criminal Force: Review of Islamic Law in \\ Contemporary Context}

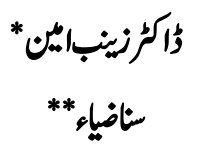

\begin{abstract}
Like the limits of crime, crimes against human life and body are also very dangerous in terms of their effects, so the Qur'an has fixed their punishment for them. Islamic law has set specific punishments for it, and it does not allow any kind of crime to be reduced. These crimes have schakled the very basis of society and they have to be dealt with severely. The basic elements of society are the need to protect the structures on which the lives and deaths of society depend. These crimes can be basically divided into two types: 1.Crimes against human beings (e.g. murder) 2.Crimes against the human body. There is a long way to go around, and in the meantime, this kind of research is needed, the seriousness of which is far greater than the rest of researches. This article examined the crimes against humanity in the light of Islamic law.
\end{abstract}

Key Words: Criminal Force, Review, Islamic law, Contemporary context

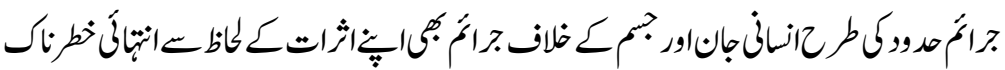

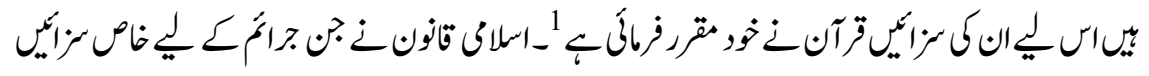

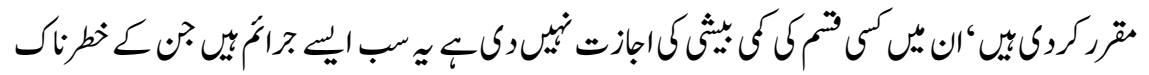

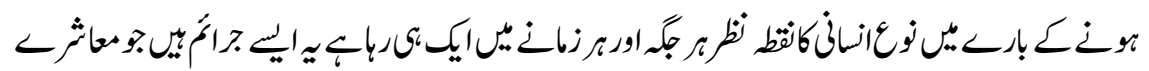

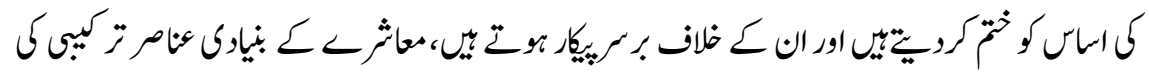

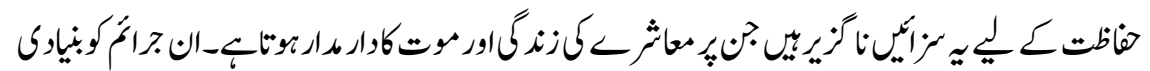

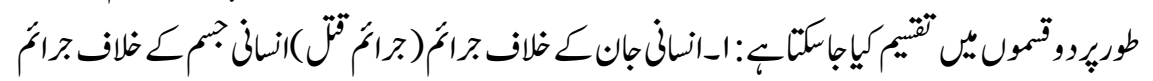

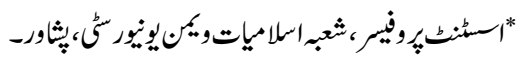

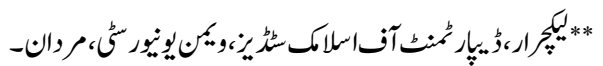




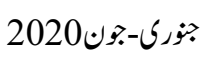

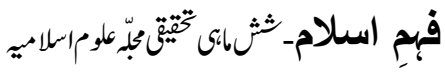

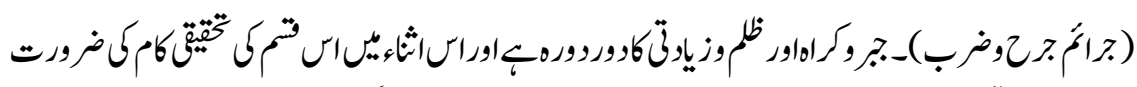

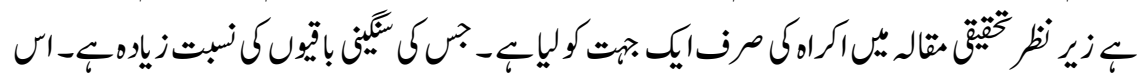

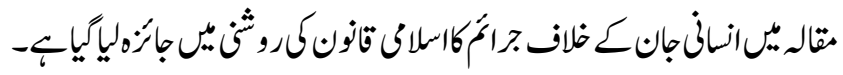

لغوى تِّف

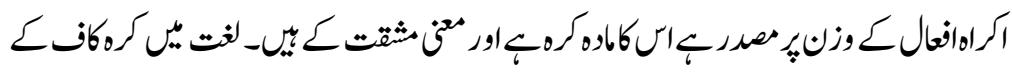

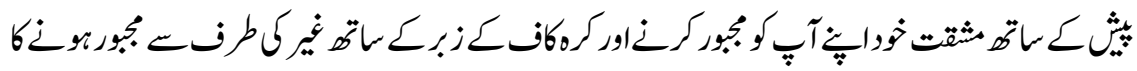

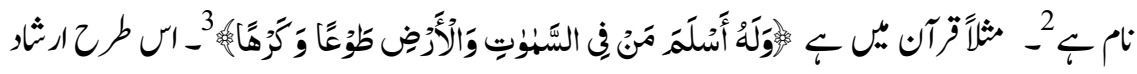

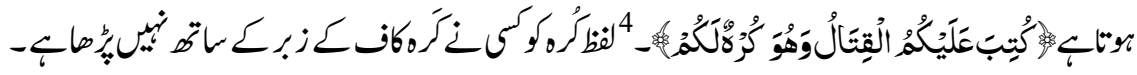

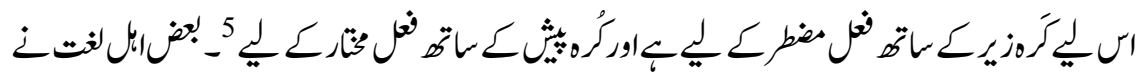

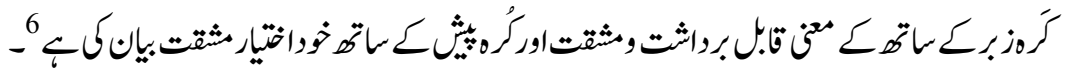

اكراهكاصطارحتخ ليف

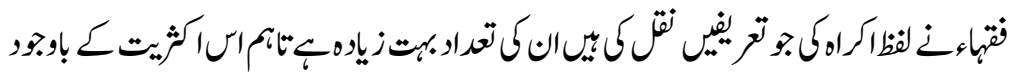

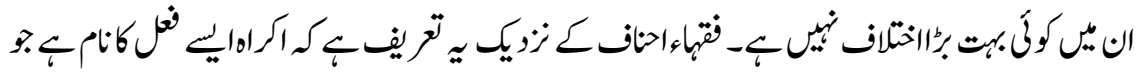

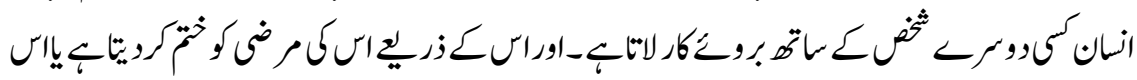

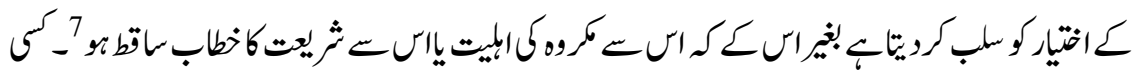

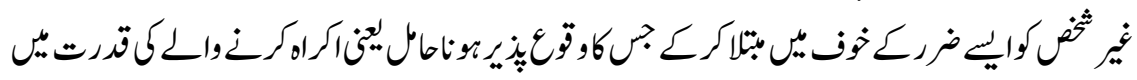

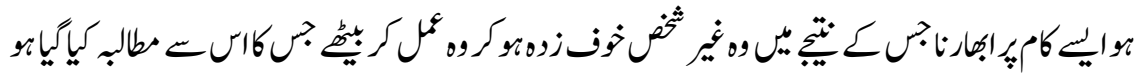

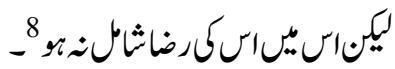

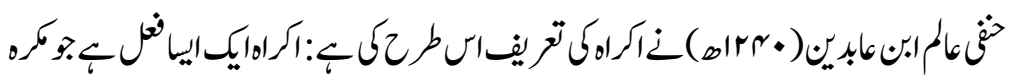

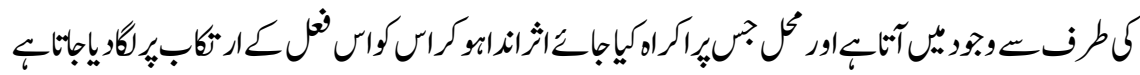

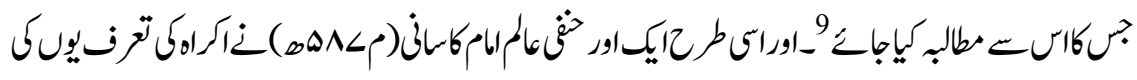

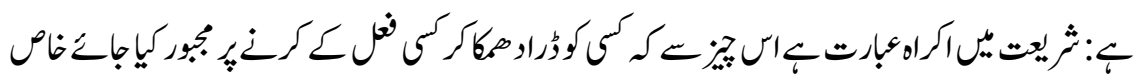

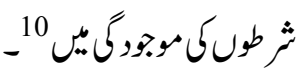

20 


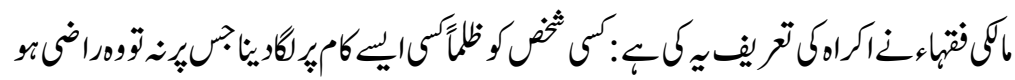

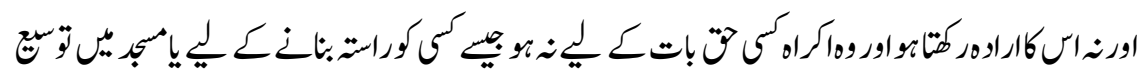

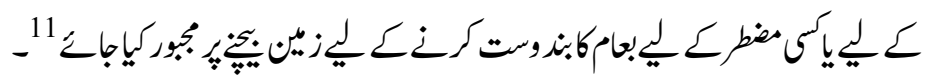

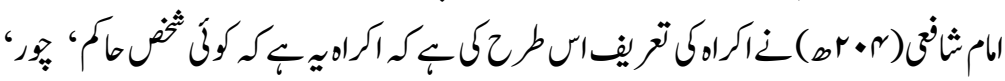

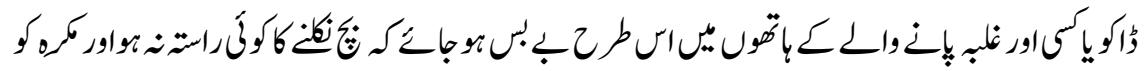

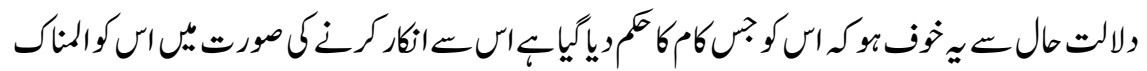

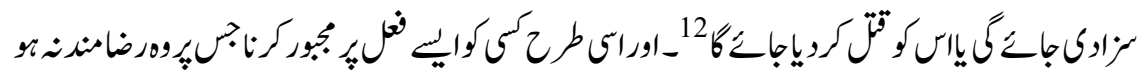

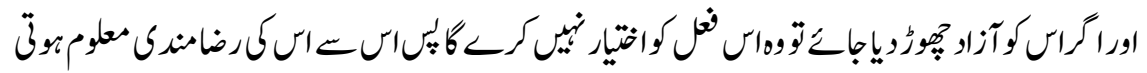
بن بحك اتتيار

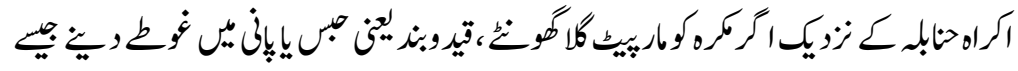

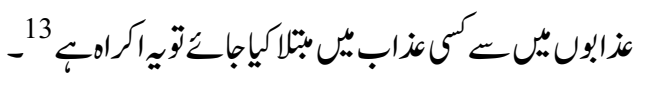

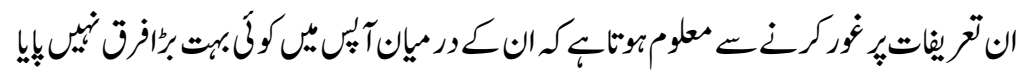

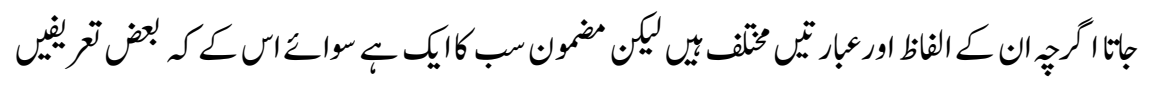

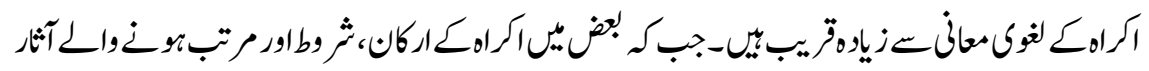

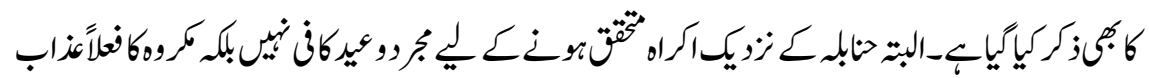

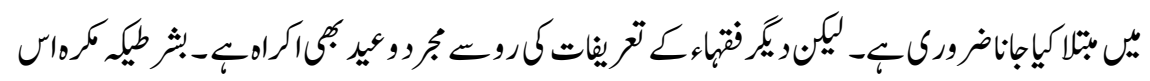

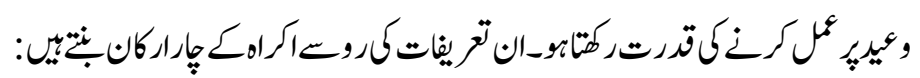

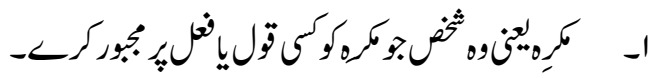
r

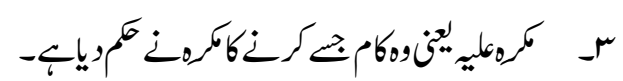

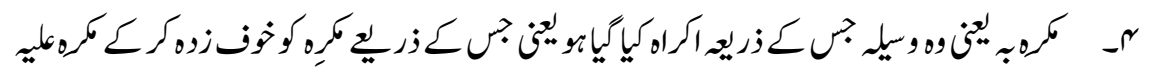

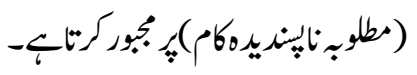

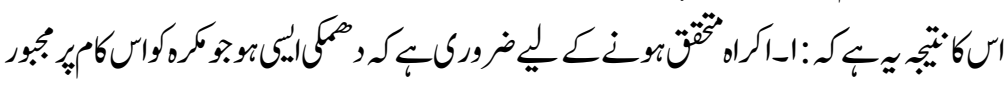

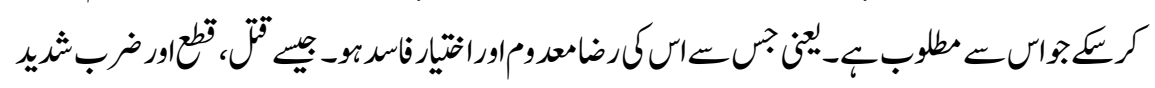




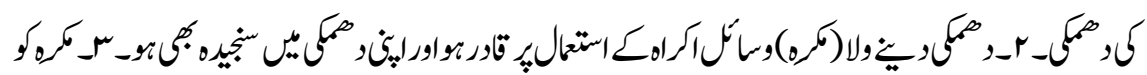

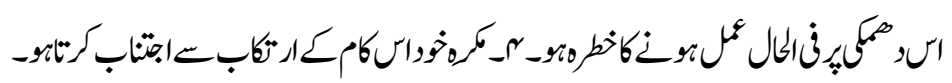

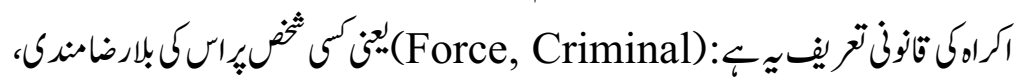

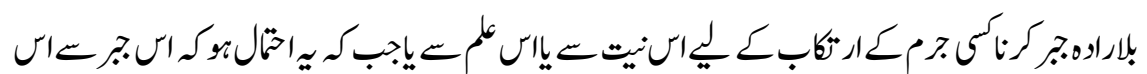

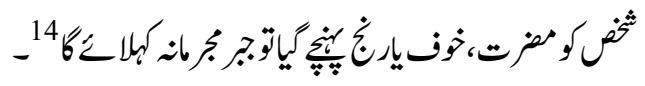

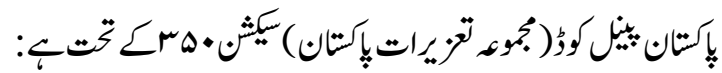

Section: 350 :A person is said to use "criminal force" to another person where the person intentionally uses force to any other person, without that person's consent..... ${ }^{15}$

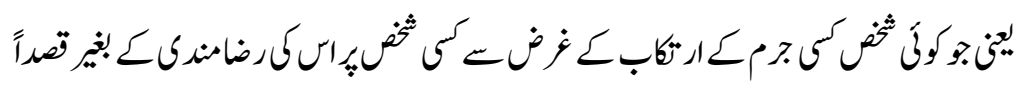

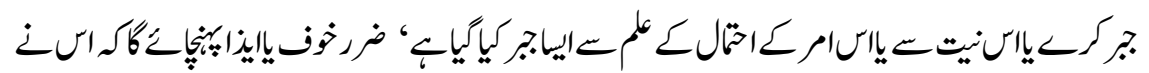

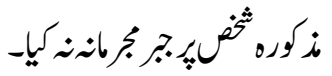

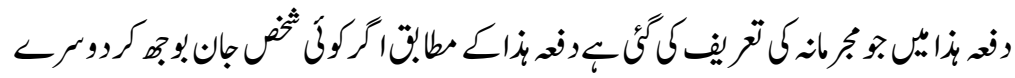

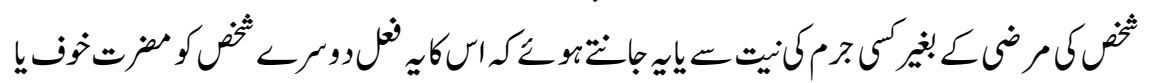

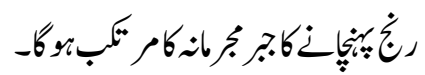

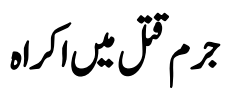

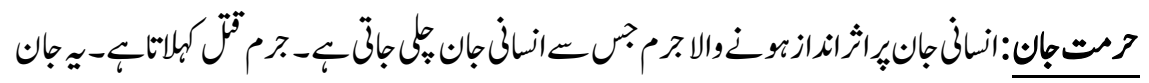

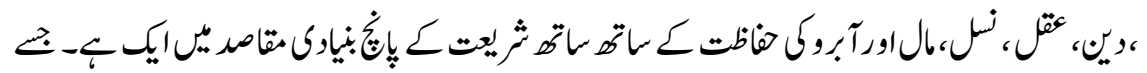

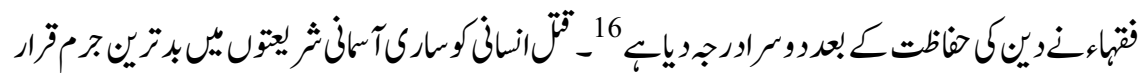

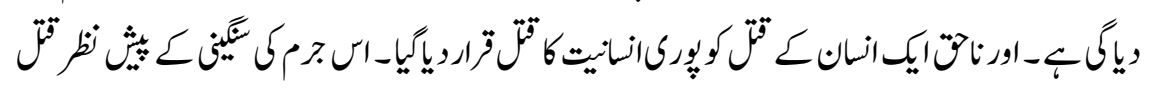

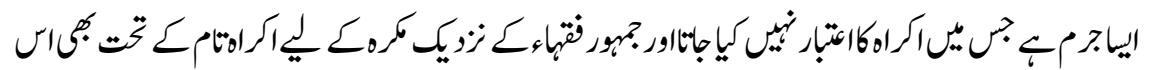

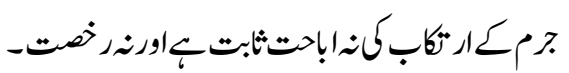




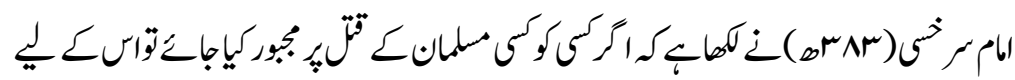

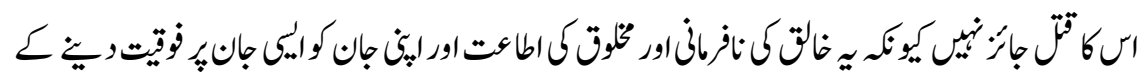

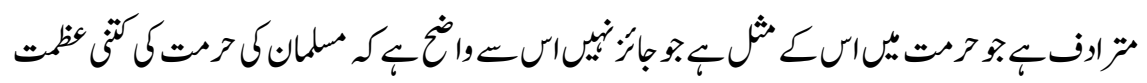

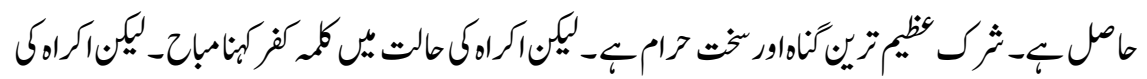

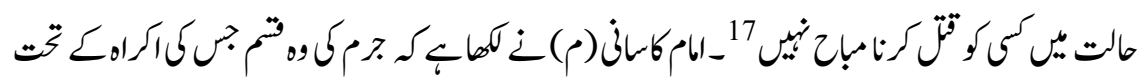

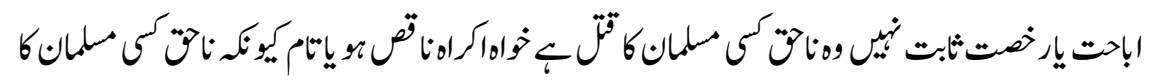

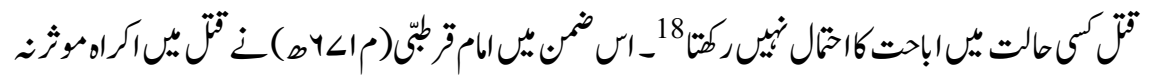

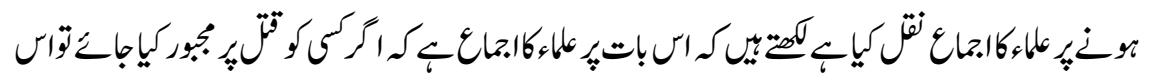

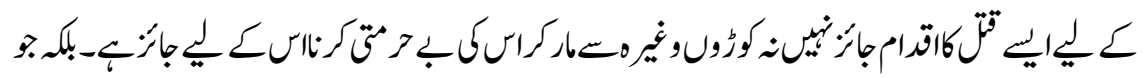

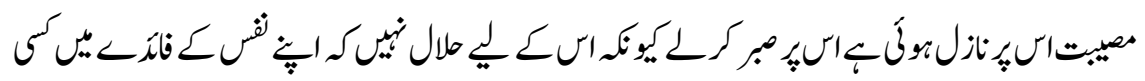

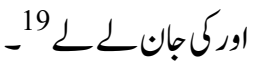

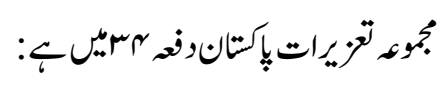

Act of Which a Person is Compelled by threats

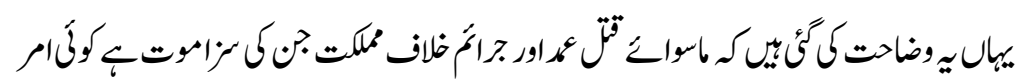

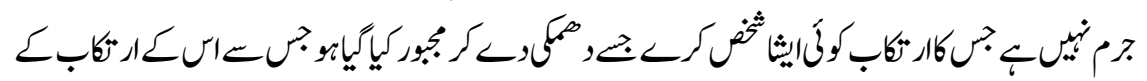

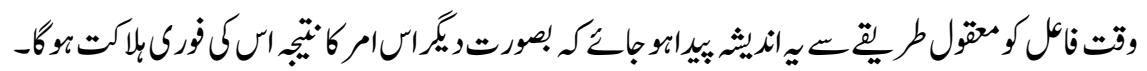

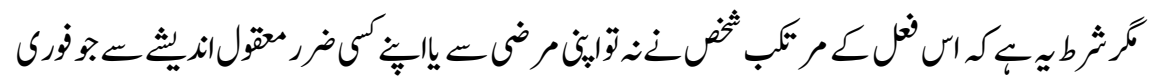

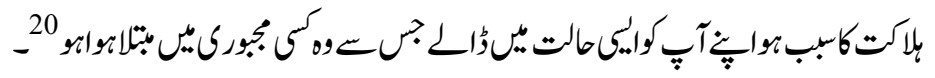

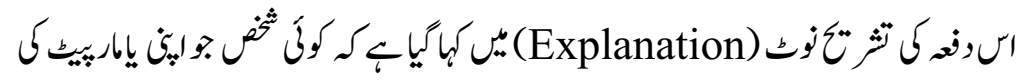

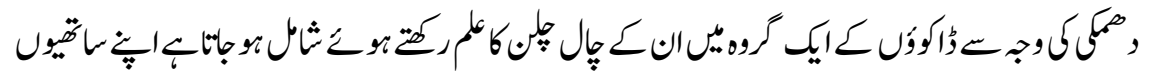

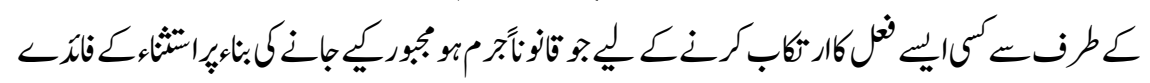

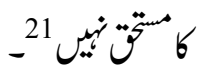

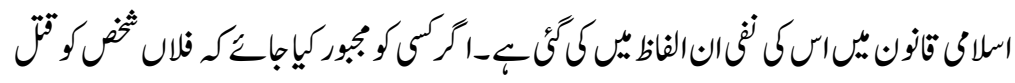

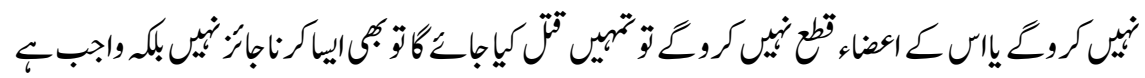




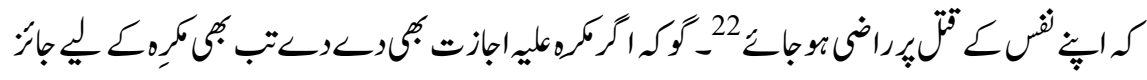

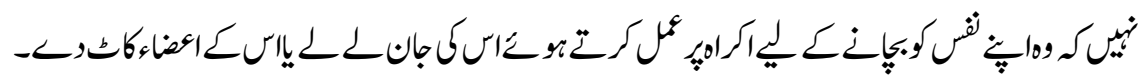

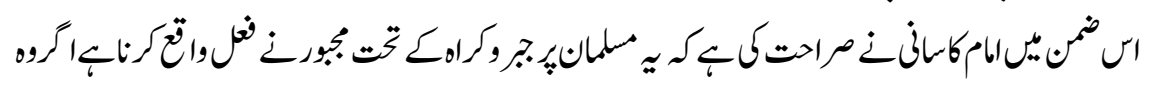

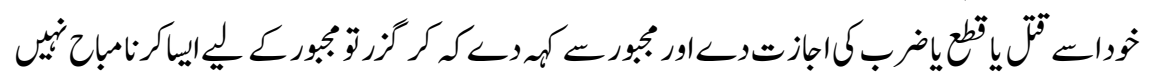

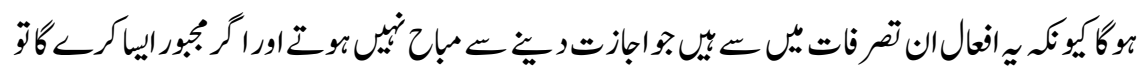

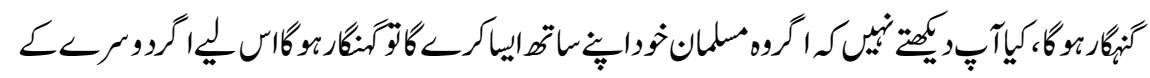

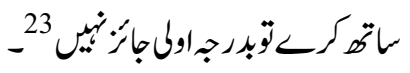

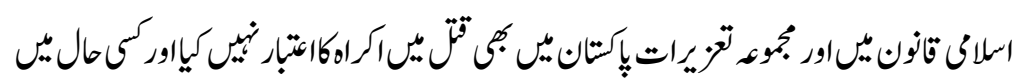

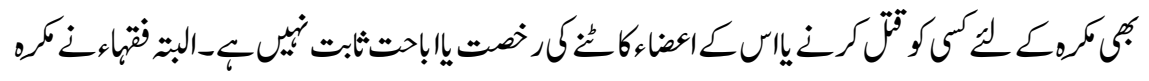

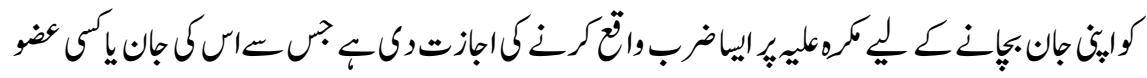

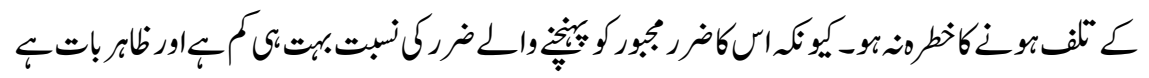

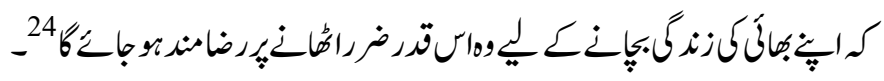

\section{اكراه كمانسانع}

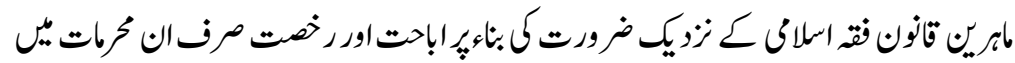

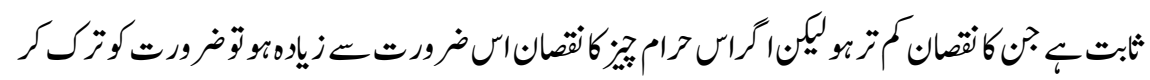

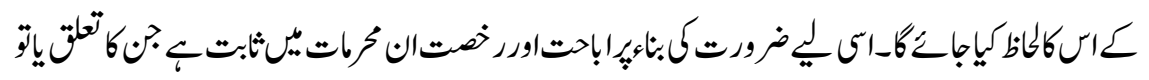

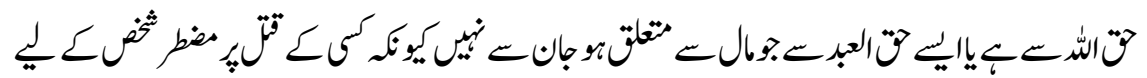

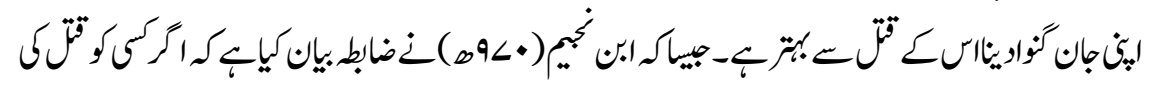

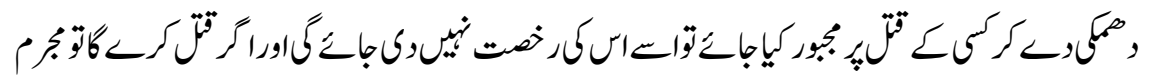

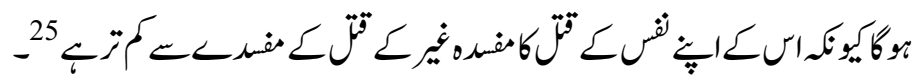

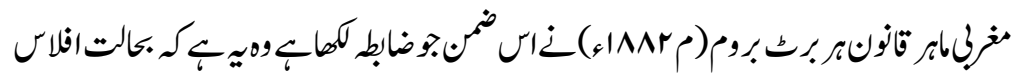

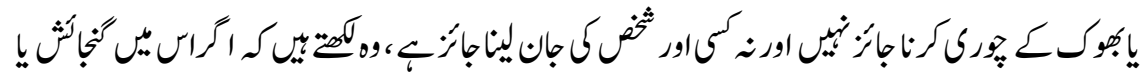

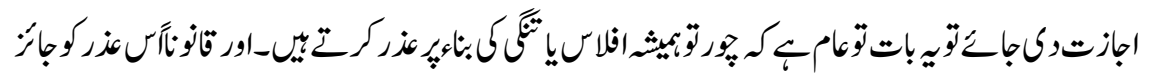




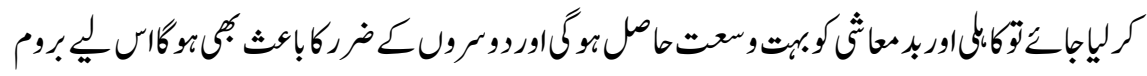

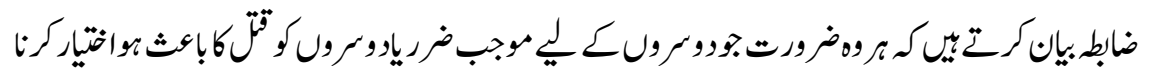

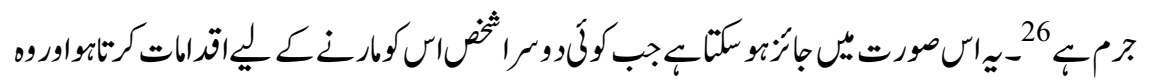

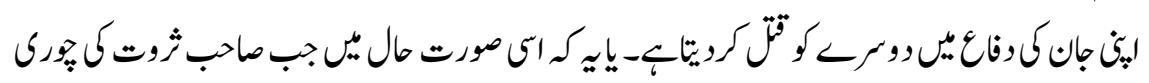

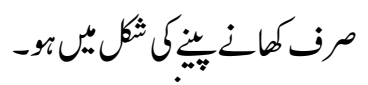

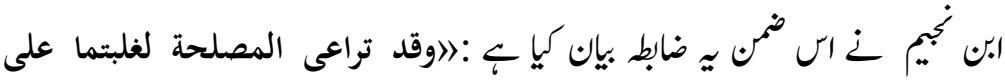

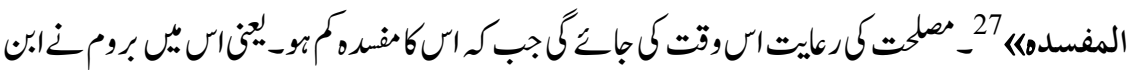

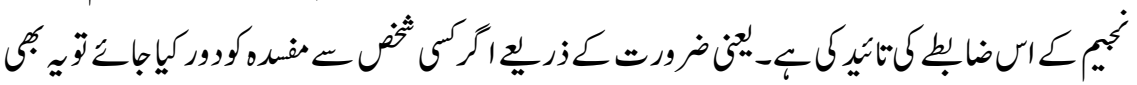

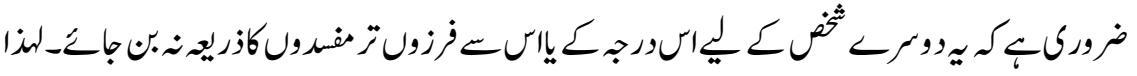

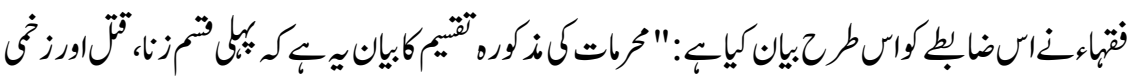

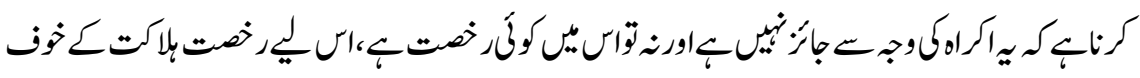

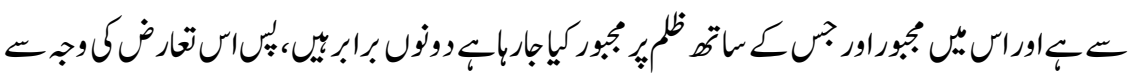

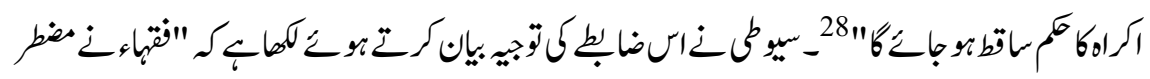

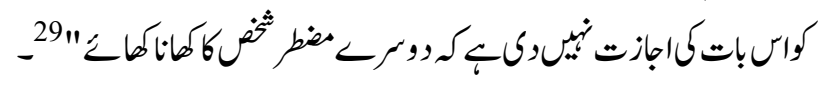

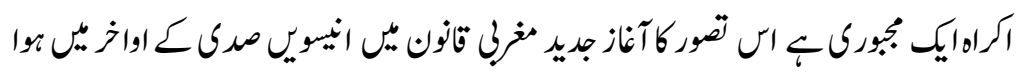

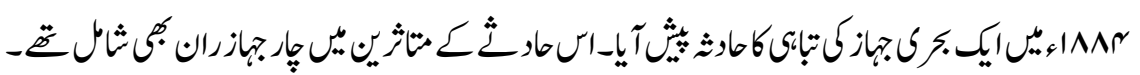

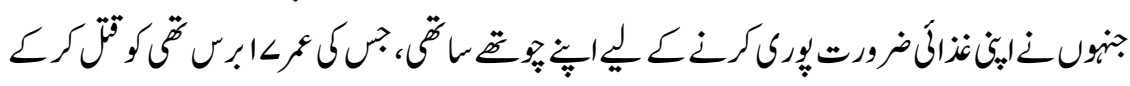

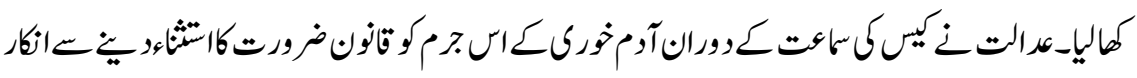

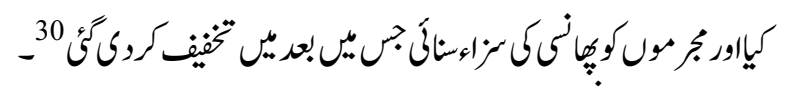

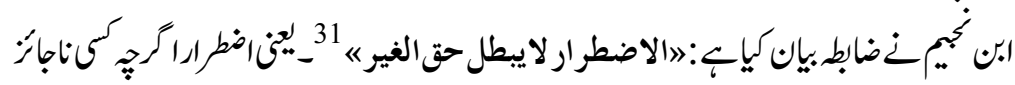

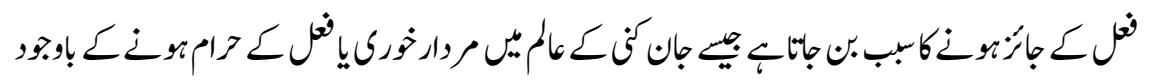

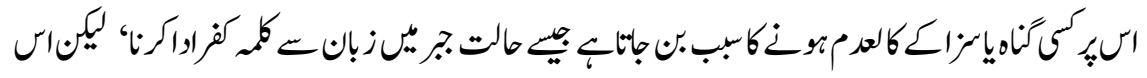

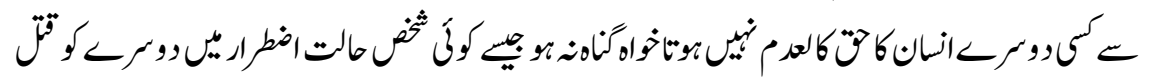




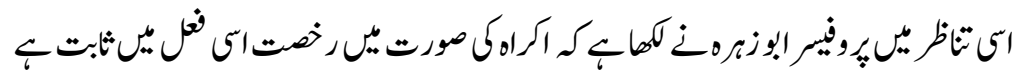

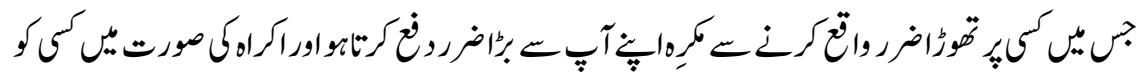

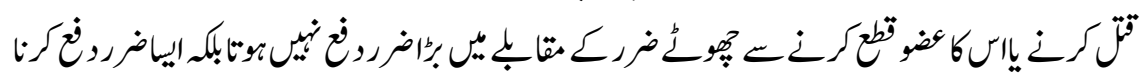

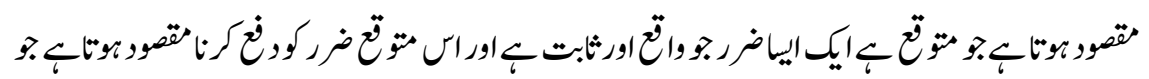

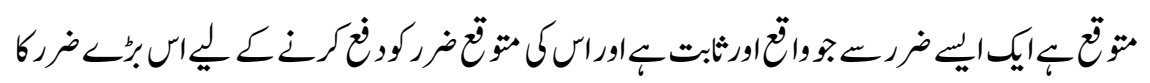

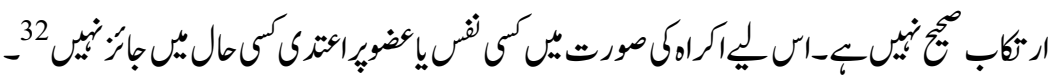

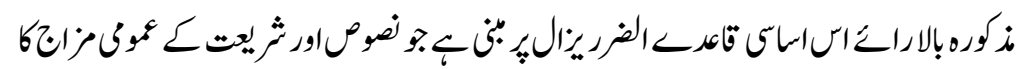

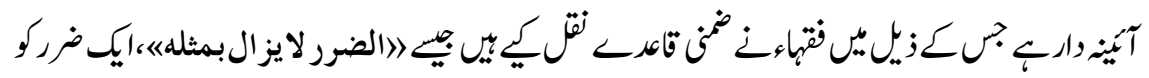

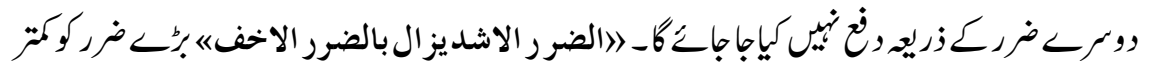

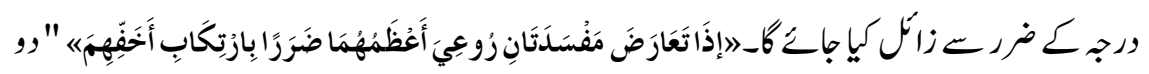

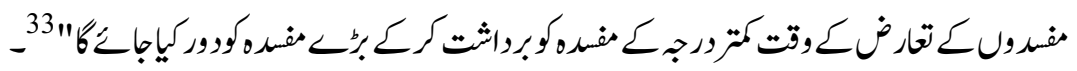

\section{قصاصويت}

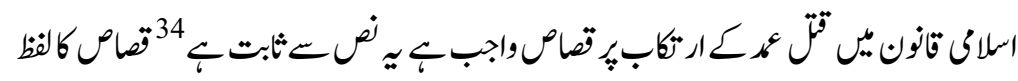

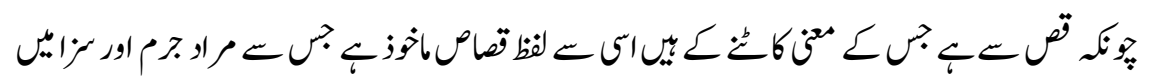

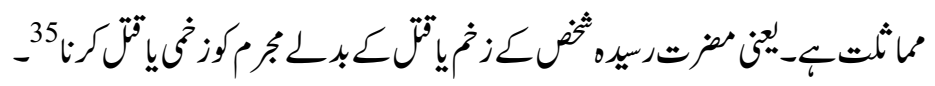

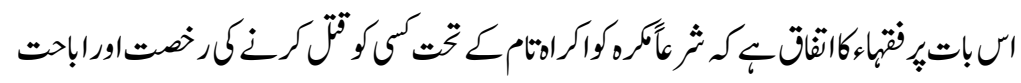

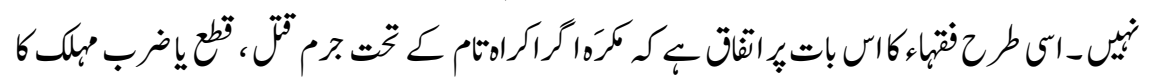

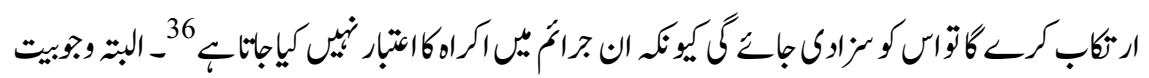

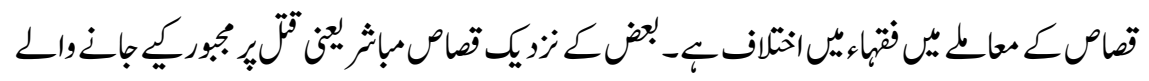

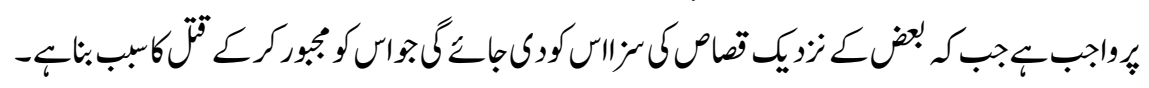

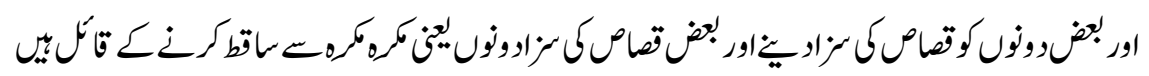




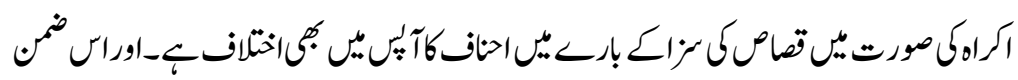

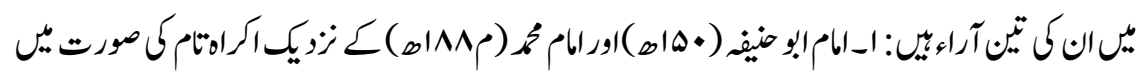

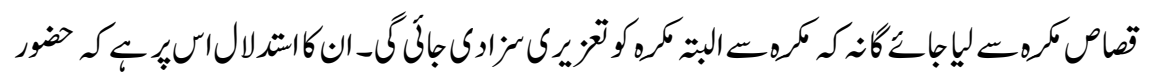

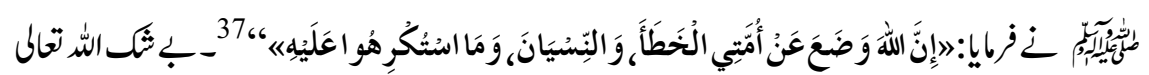

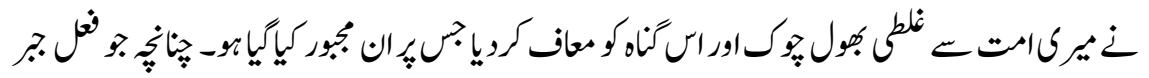

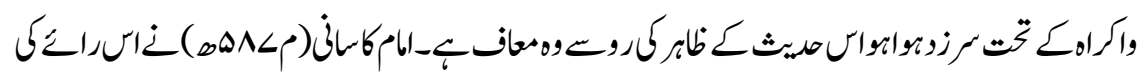

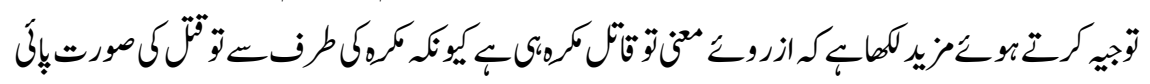

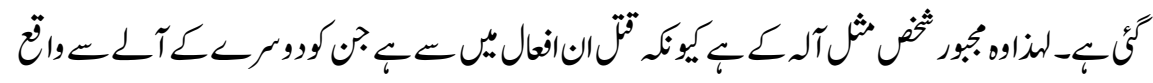

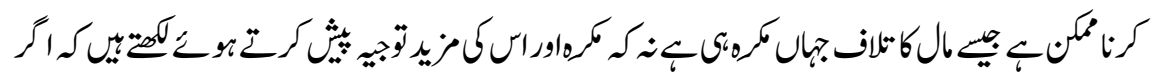

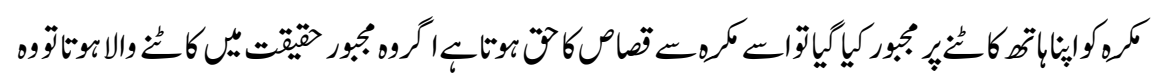

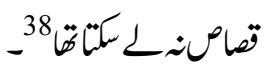

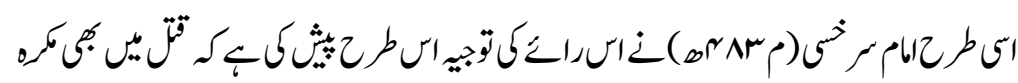

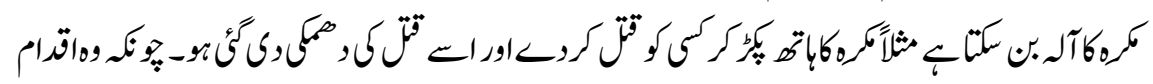

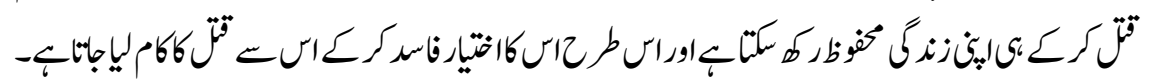

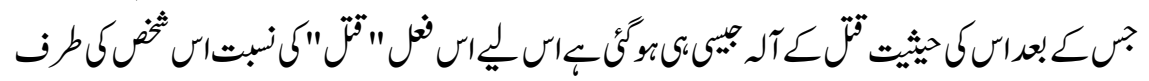

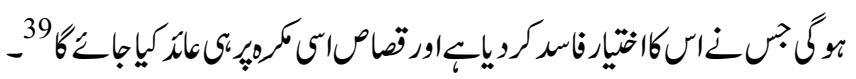

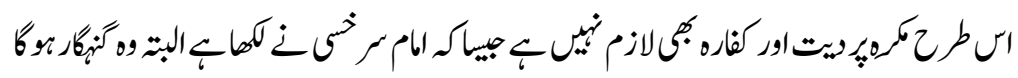

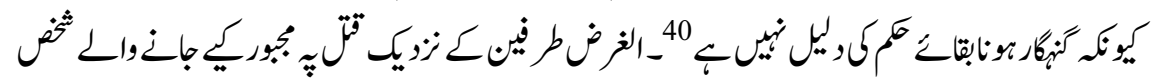

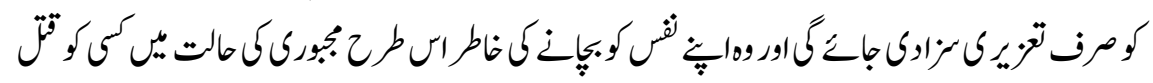

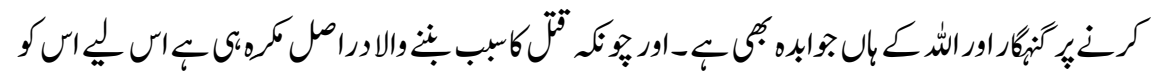

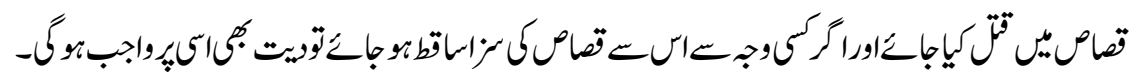

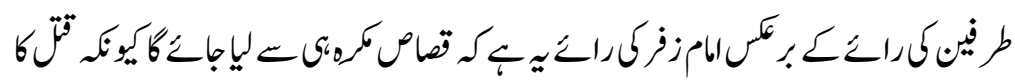

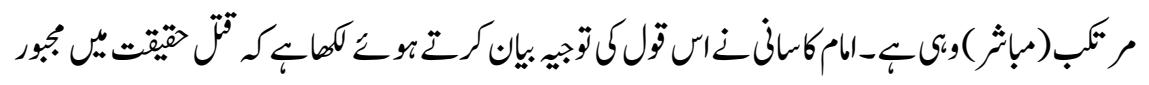

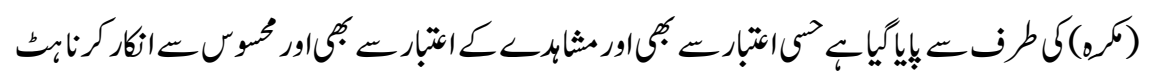




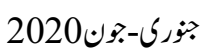

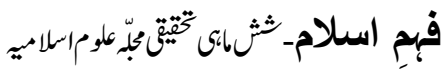

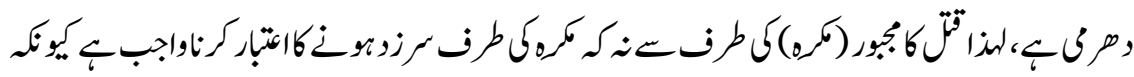

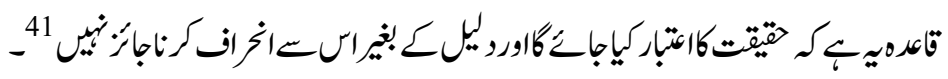

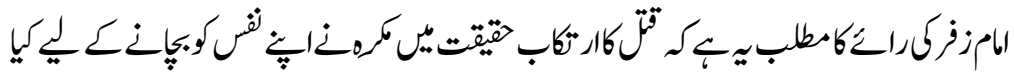

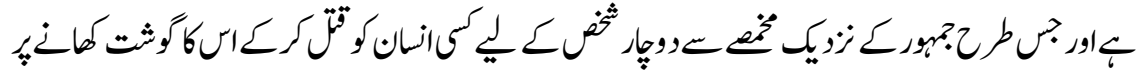

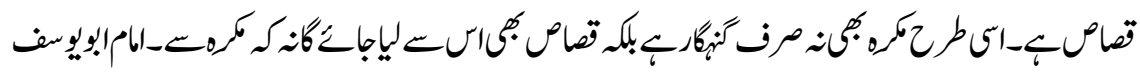

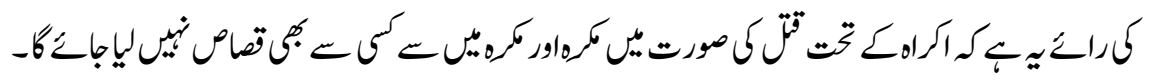

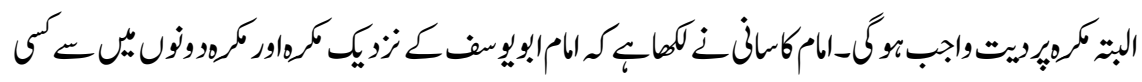

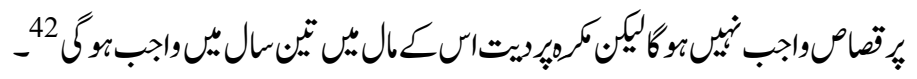

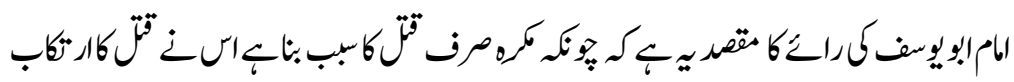

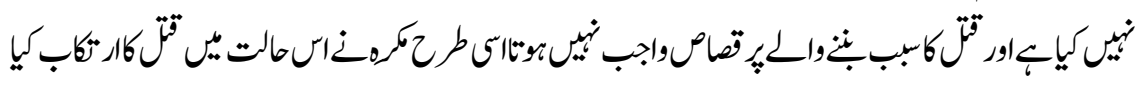

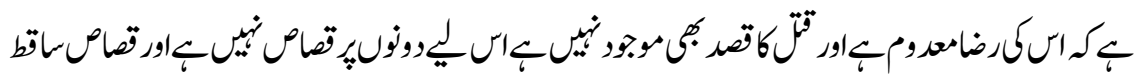

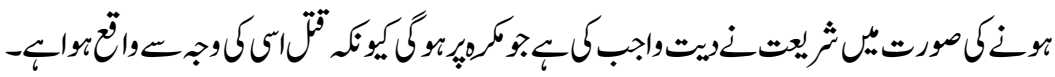

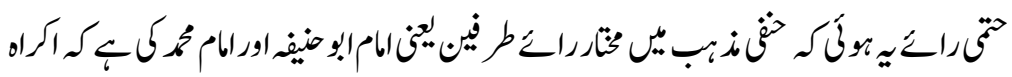

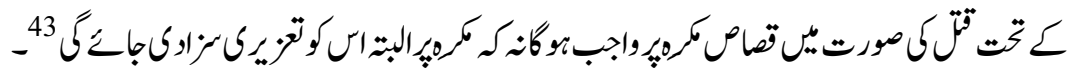

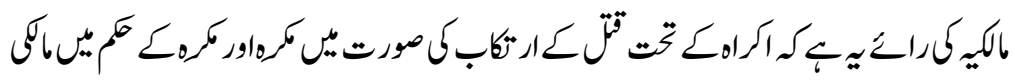

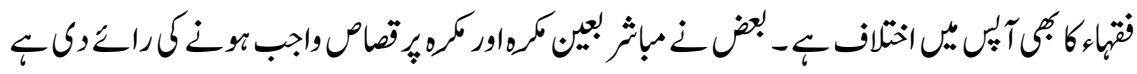

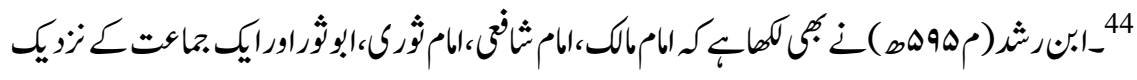

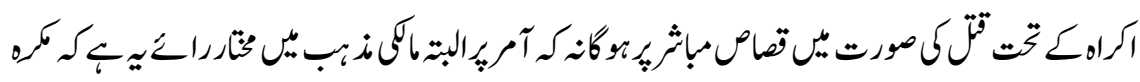

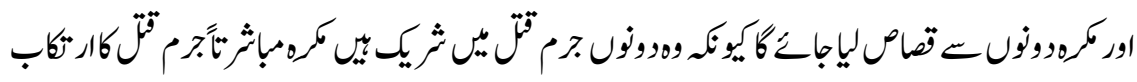

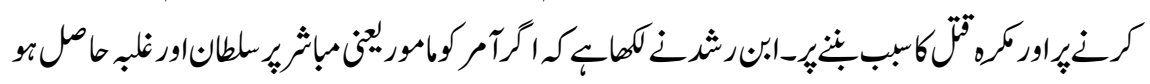

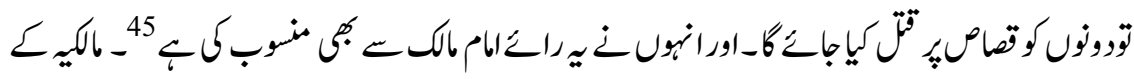

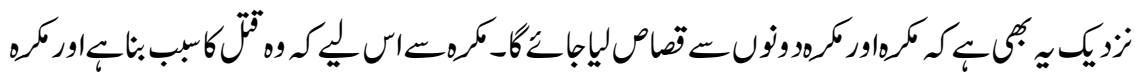

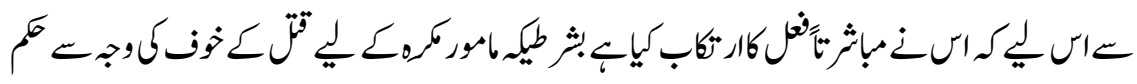

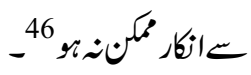

28 


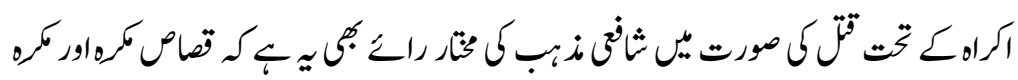

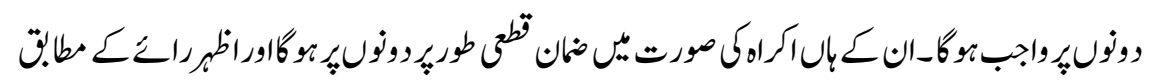

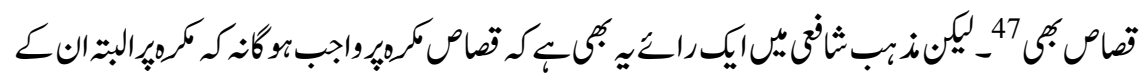

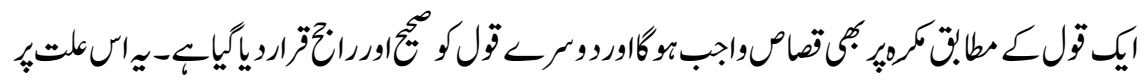

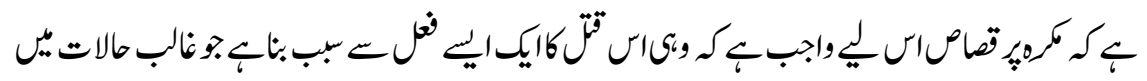

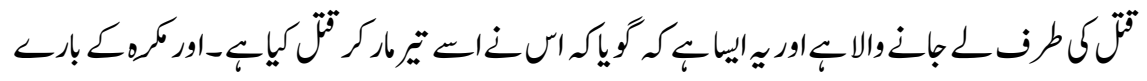

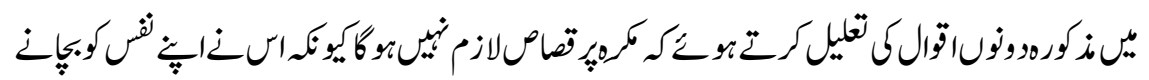

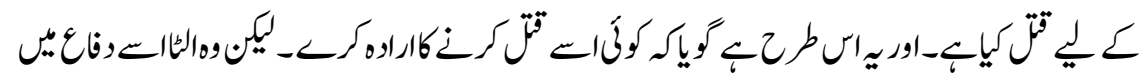

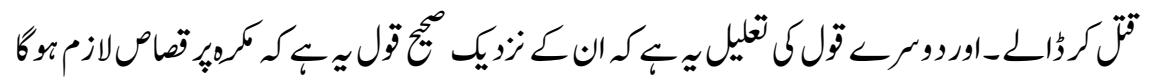

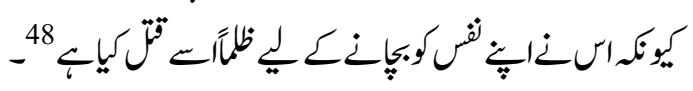

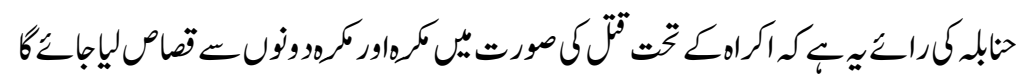

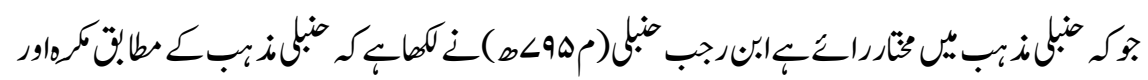

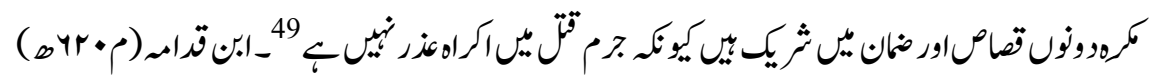

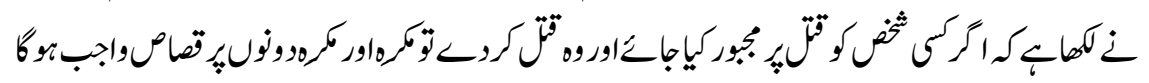

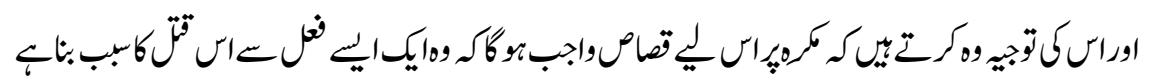

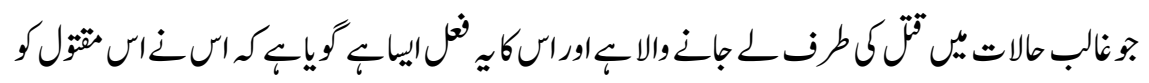

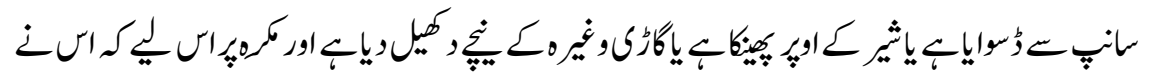

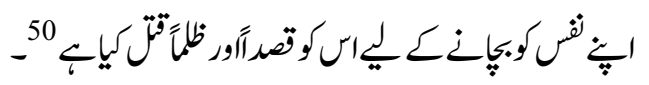

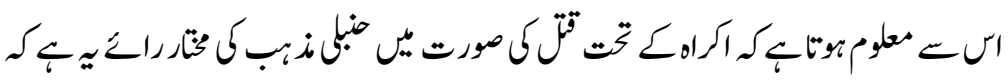

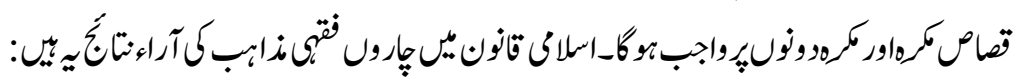

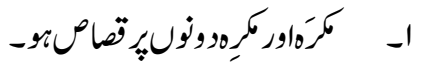

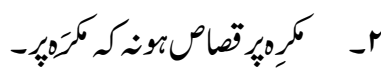

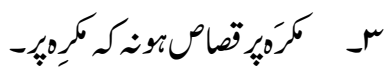




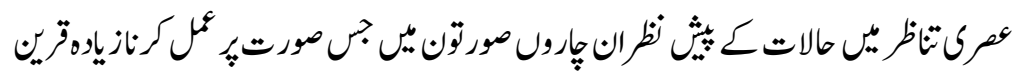

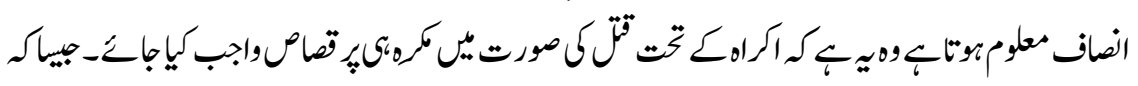

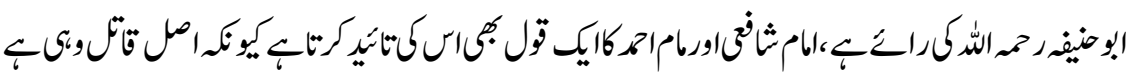

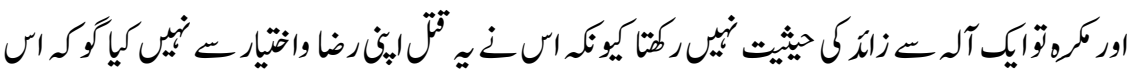

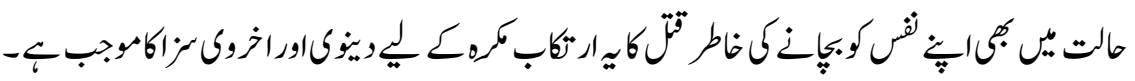

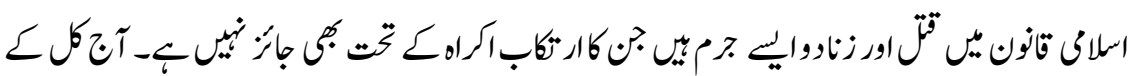

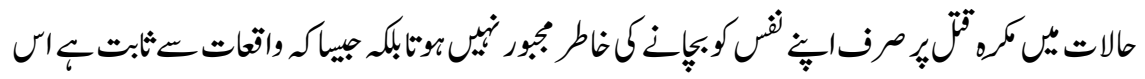

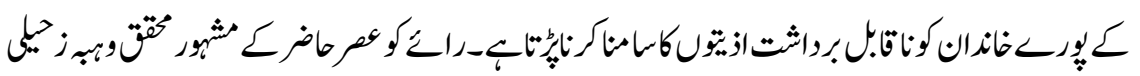

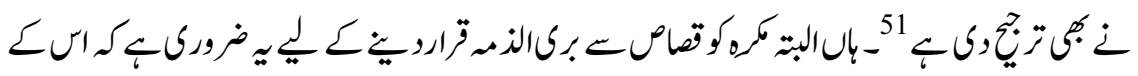

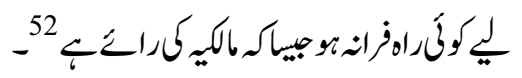

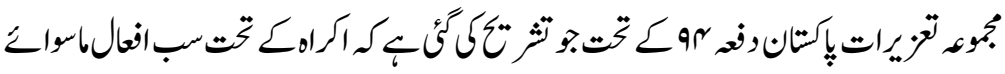

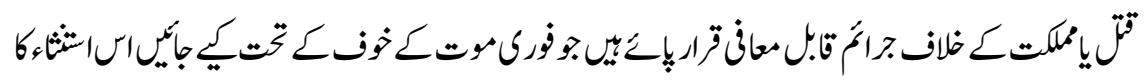

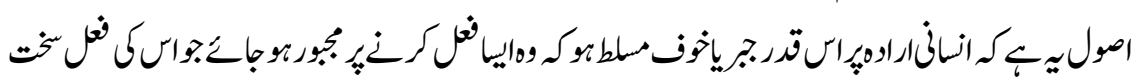

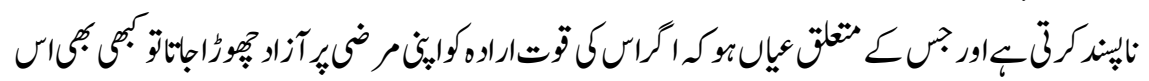

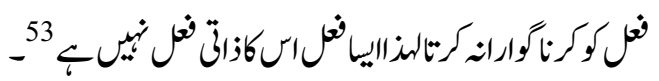

\section{موجب تز كمئكاك}

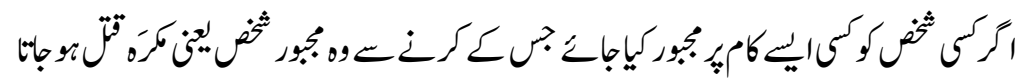

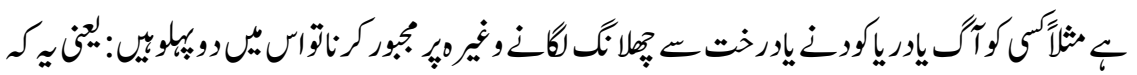

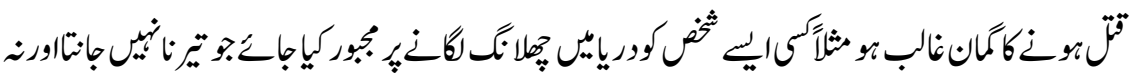

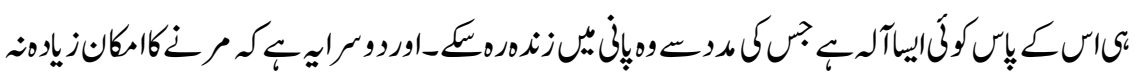

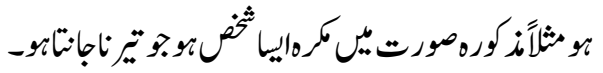

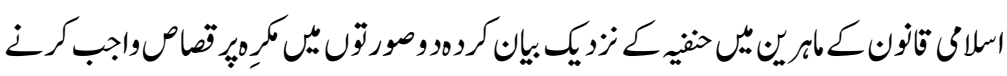

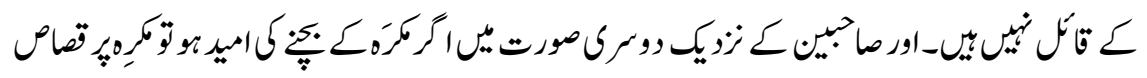




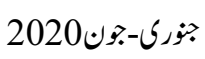

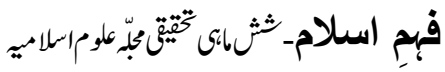

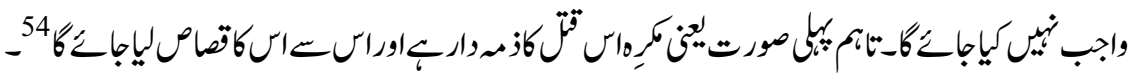

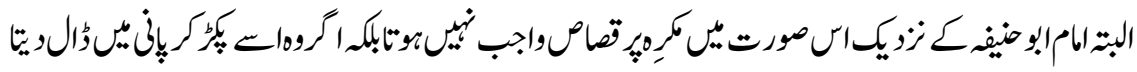

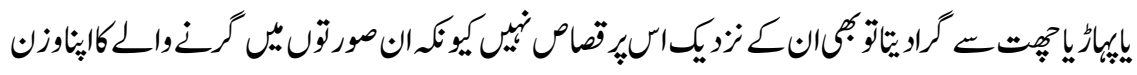

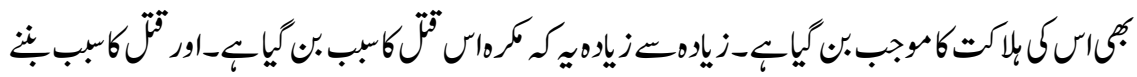

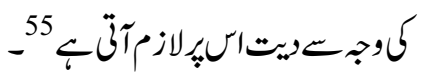

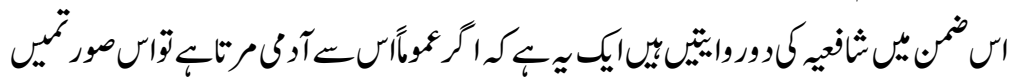

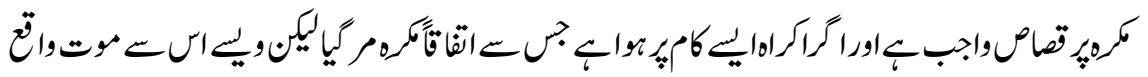

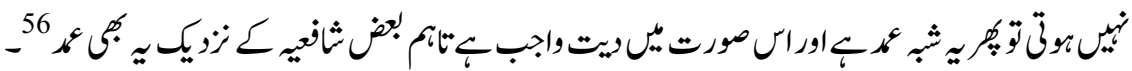

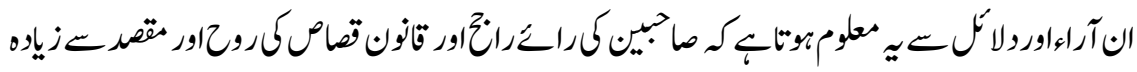

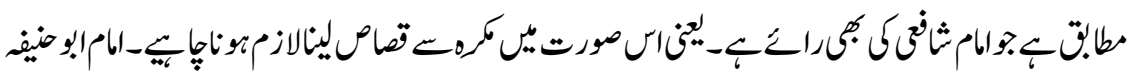

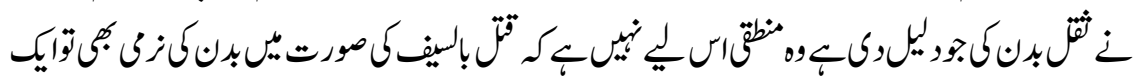
سبب

اكراهك صورت مئصيت

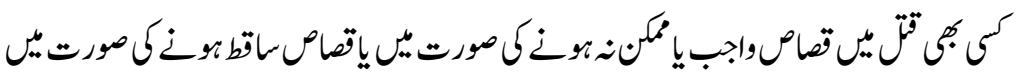

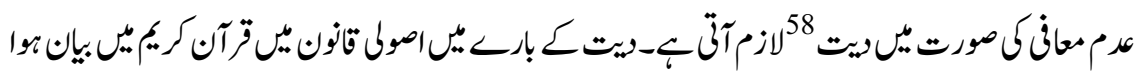

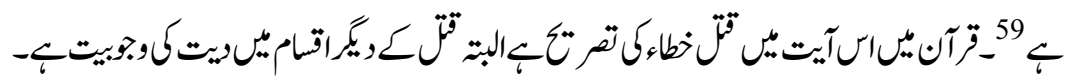

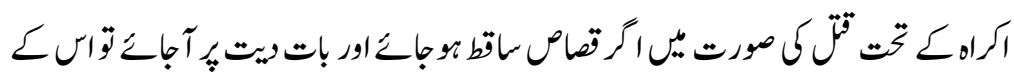

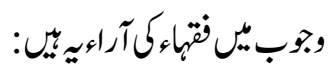

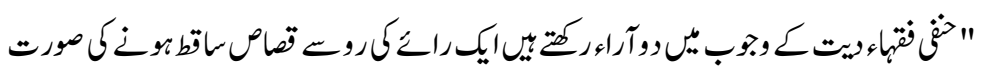

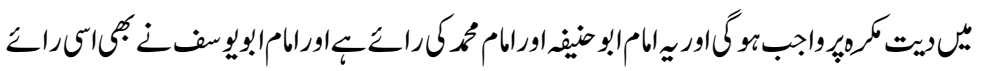

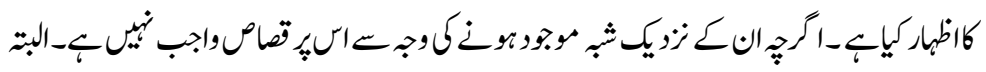

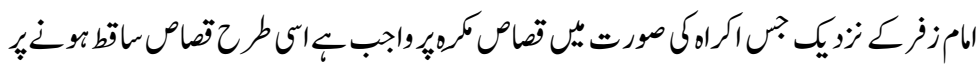

ويت بكاسيرواجب،وك"

31 


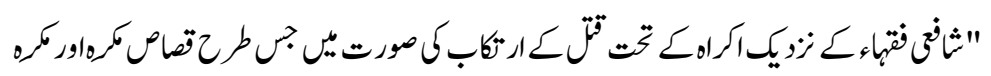

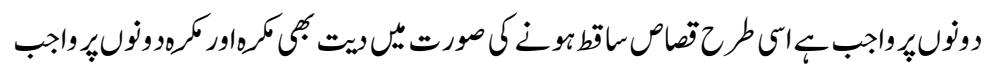

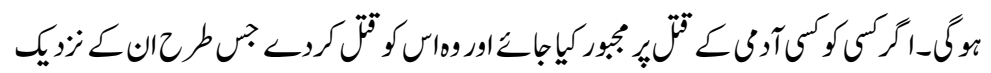

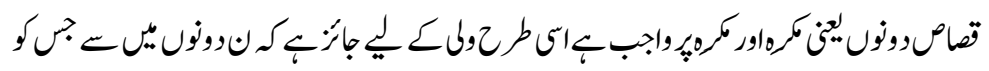

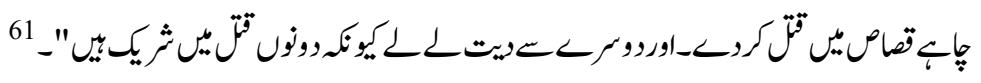

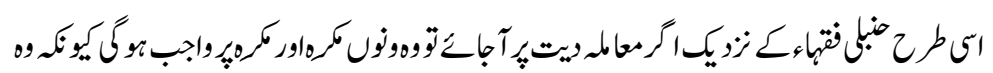

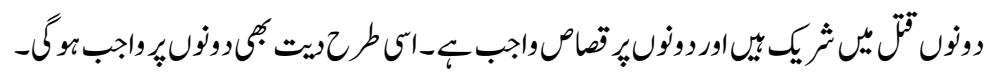

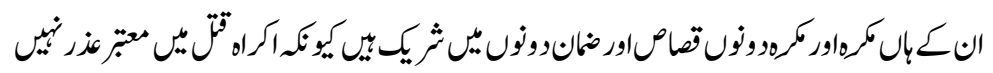

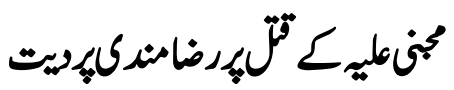

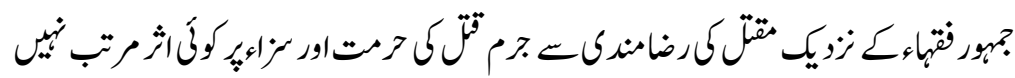

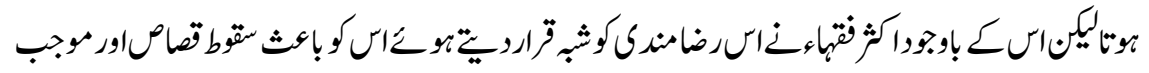

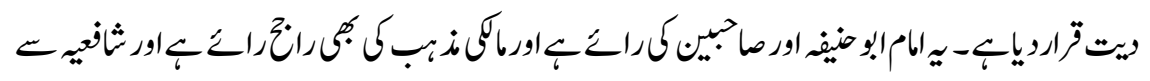

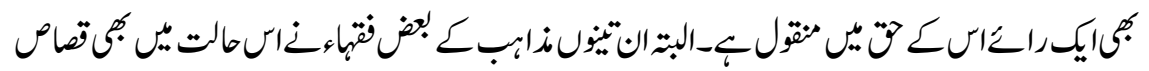
كنواجبكياك

\section{اكماهاور تّمهور}

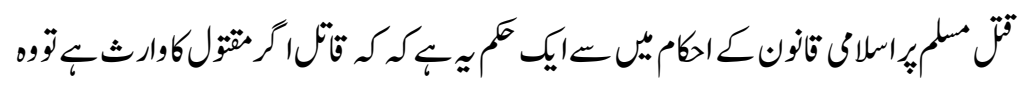

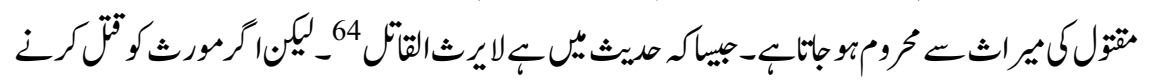

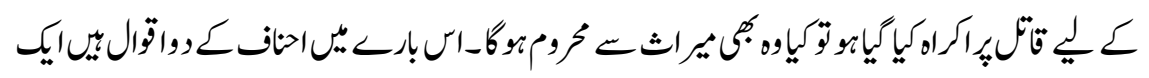

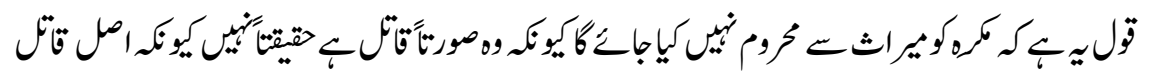

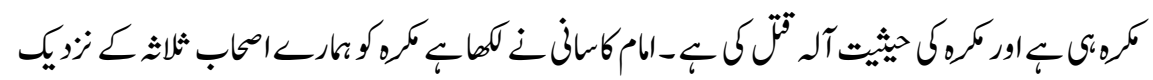

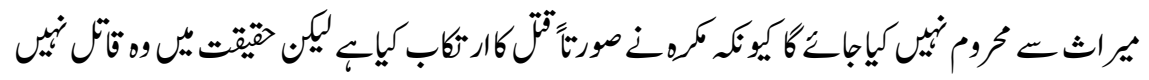




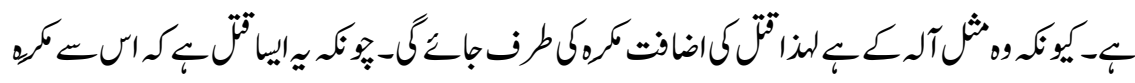

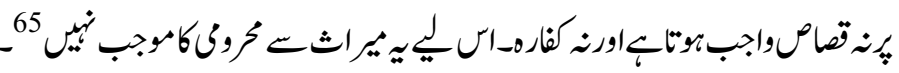

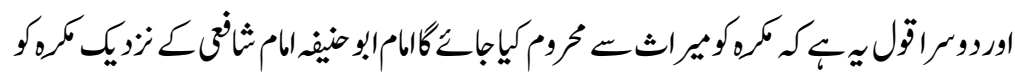

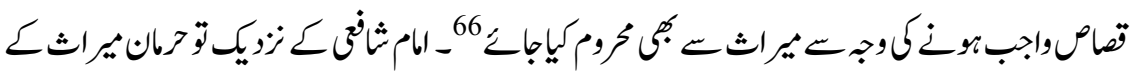

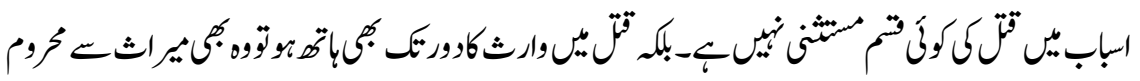

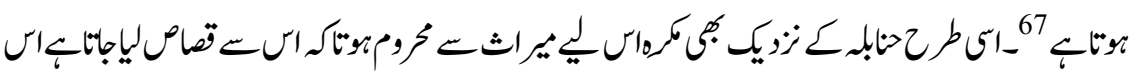

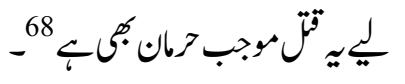

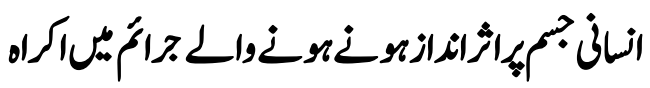

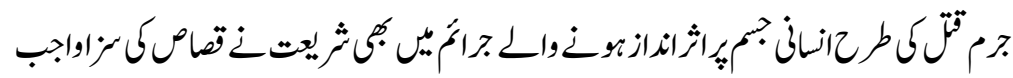

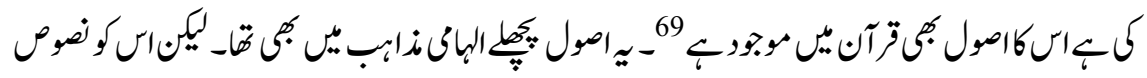

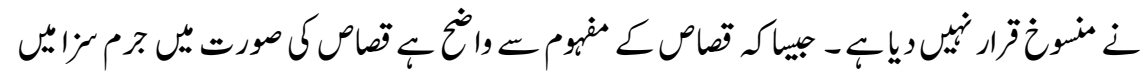

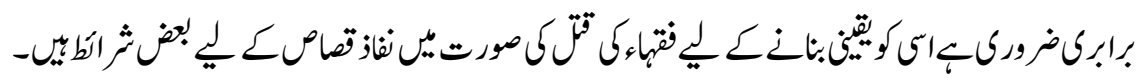

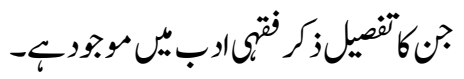

\section{اكراهـتت قطعاراف}

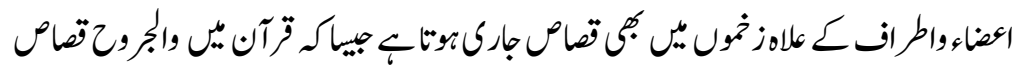

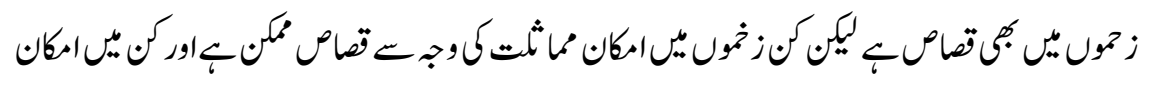

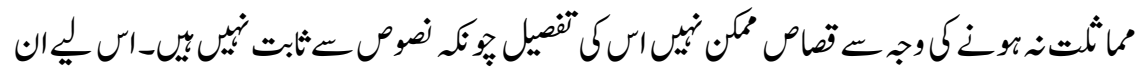

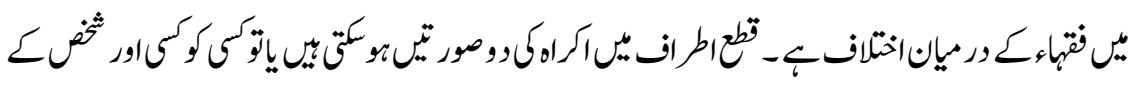

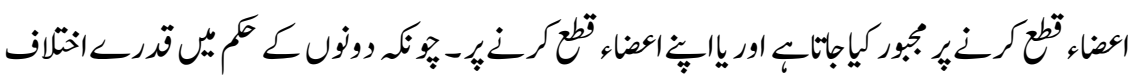

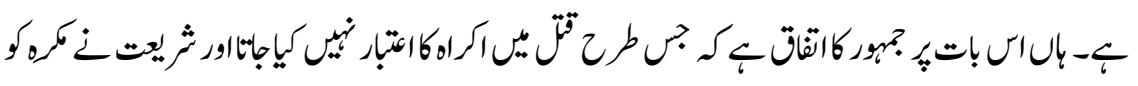

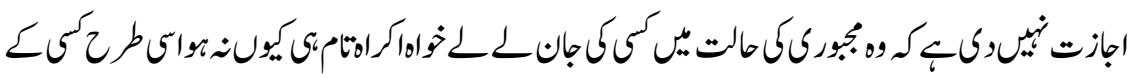

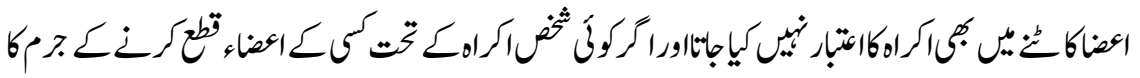




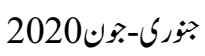

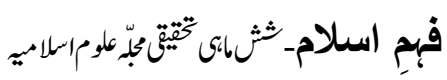

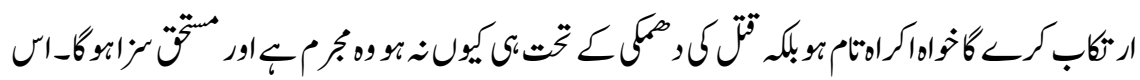

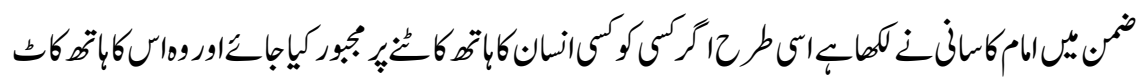

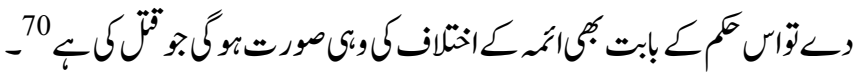

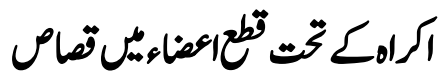

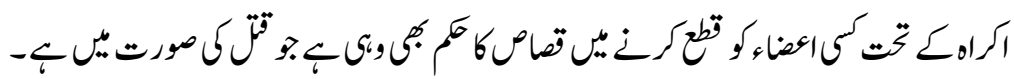

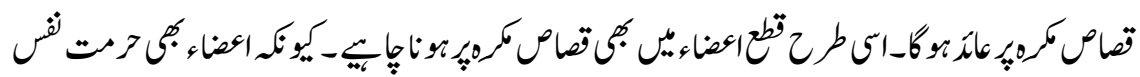

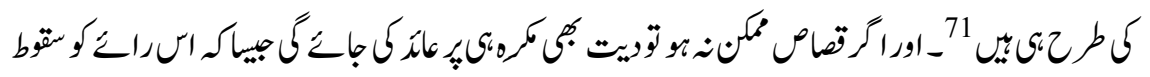

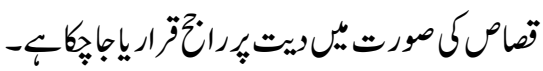

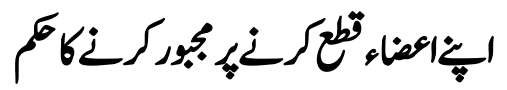

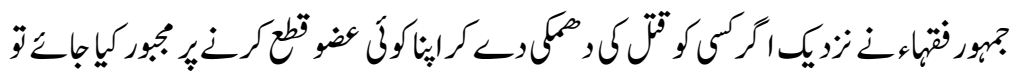

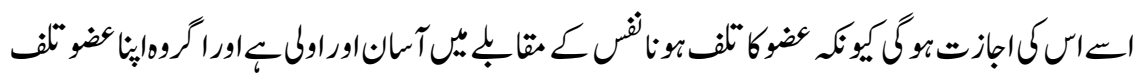

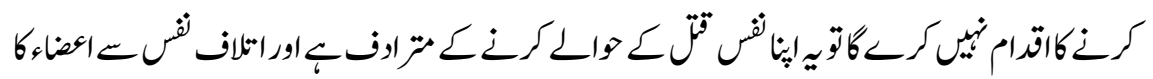

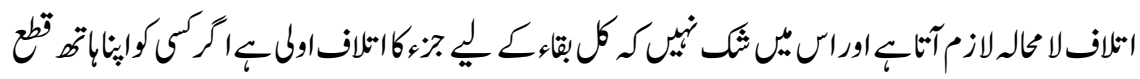

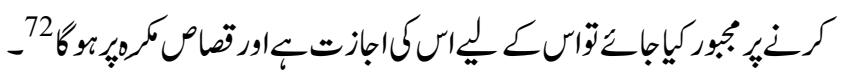

ثاصم ونتج

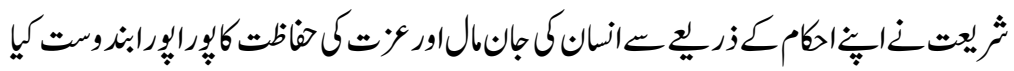

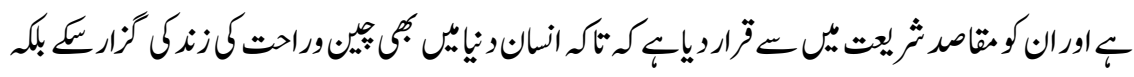

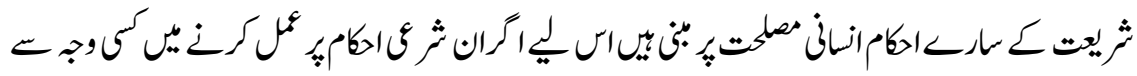

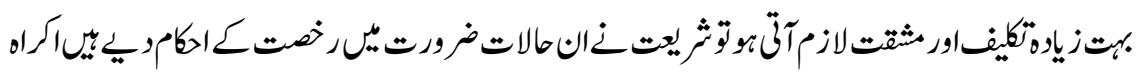

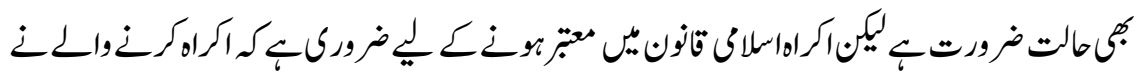

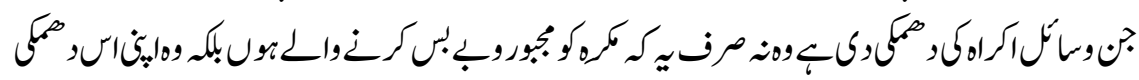

34 


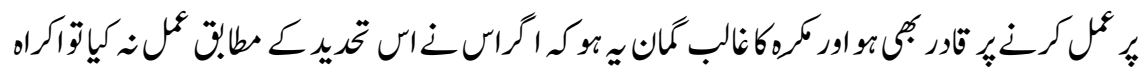

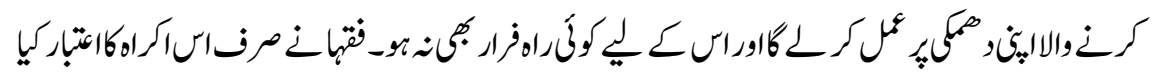

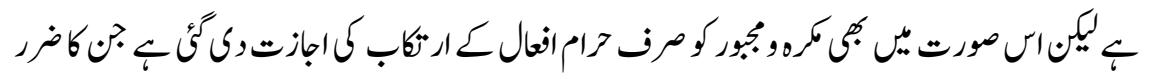

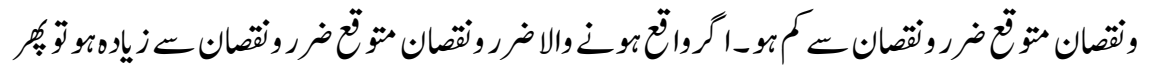

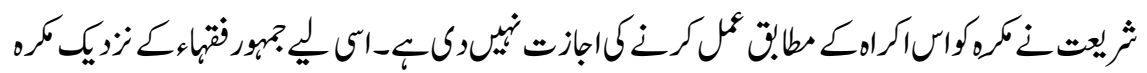

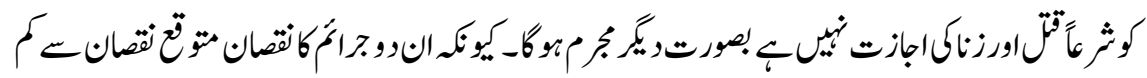

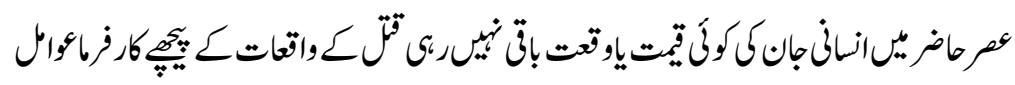

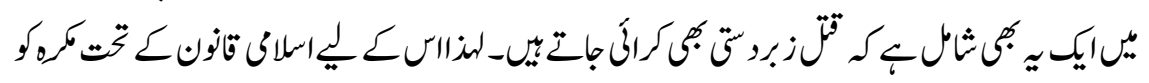

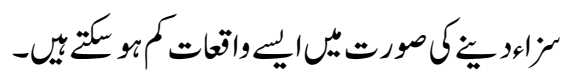

\section{واشّىو واله جات}

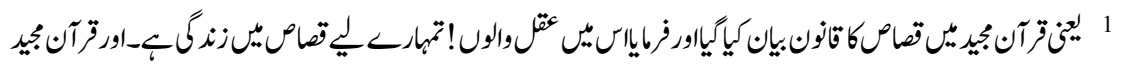

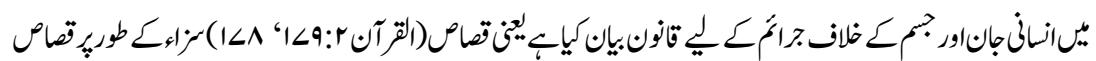

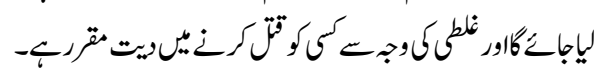

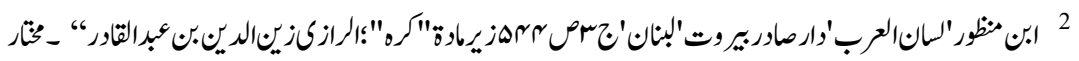

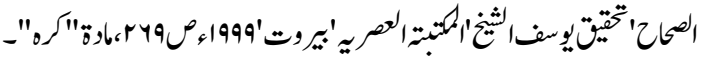

$$
\begin{aligned}
& 3 \text { الترآنس:سمـ }
\end{aligned}
$$

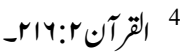

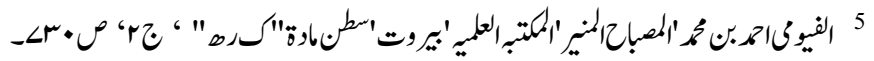

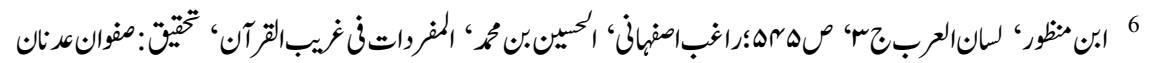

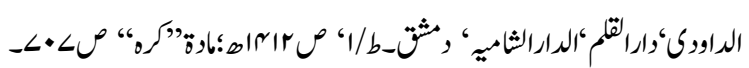

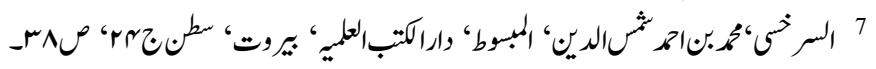

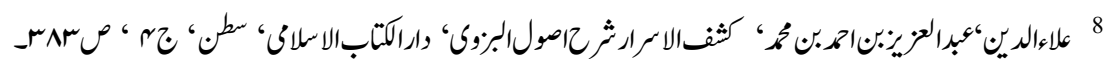

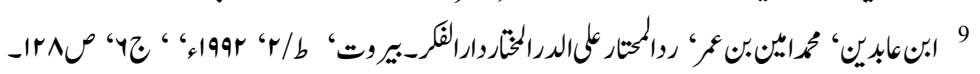

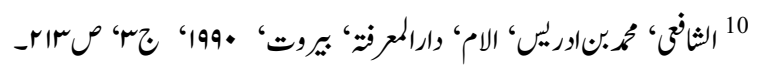




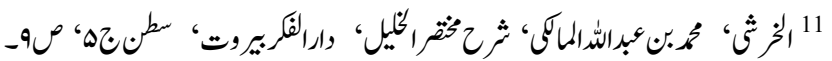

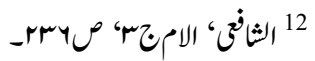

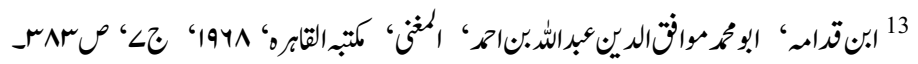

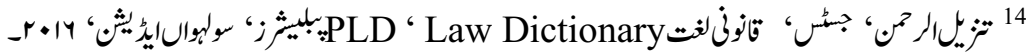

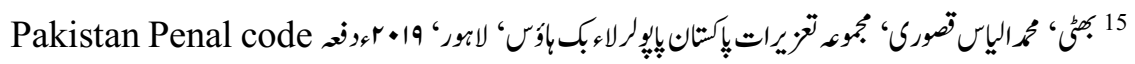

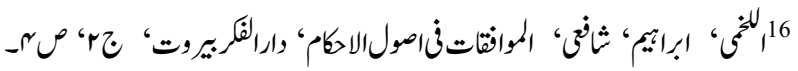

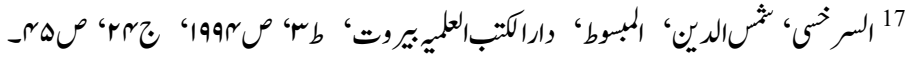

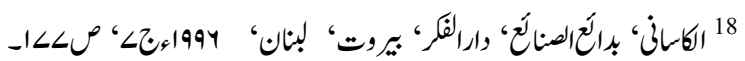

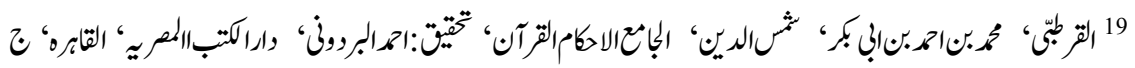

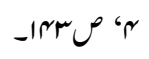

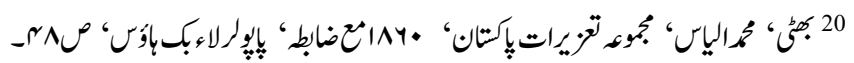

$$
21
$$

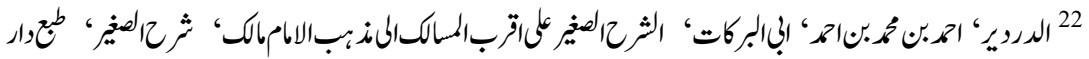

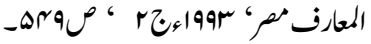

$$
\begin{aligned}
& \text { 23 }
\end{aligned}
$$

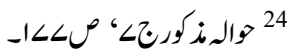

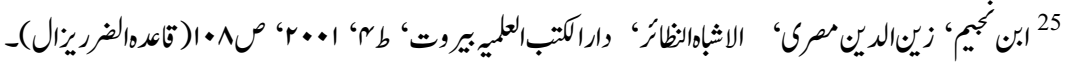

${ }^{26}$ Broom , Herbert Legal Maxim Law booksellers Publishers and Importees 1872, Philadelphia, p.145.

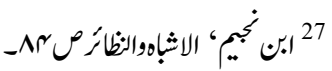

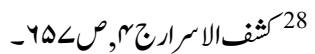

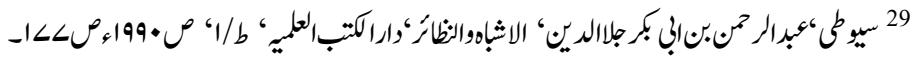

${ }^{30}$ Broom's legal Maxims p 131.

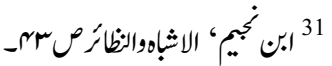

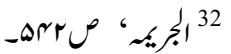

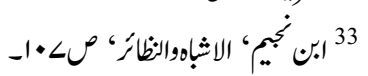




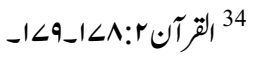

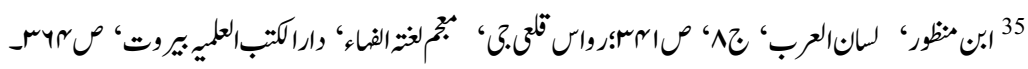

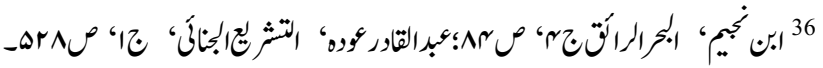

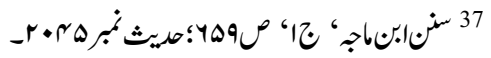

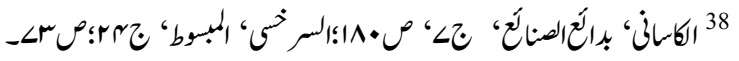

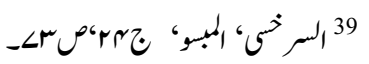
40 41

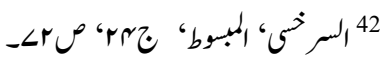

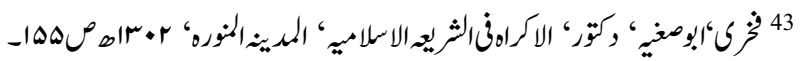

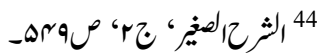

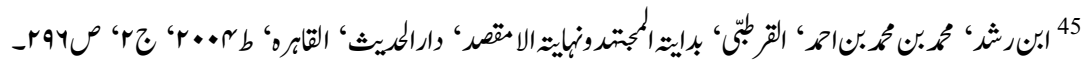

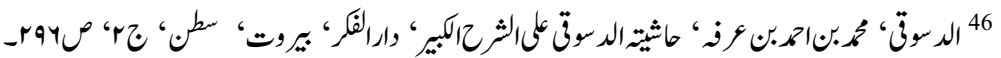

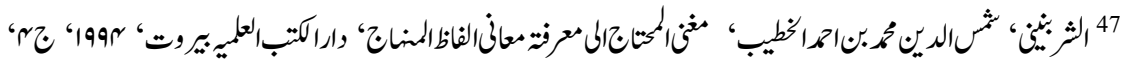

$$
\text { r.re }
$$

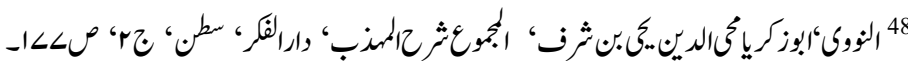

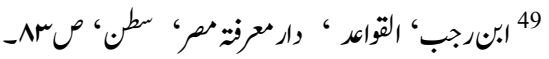

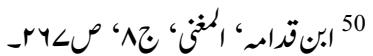

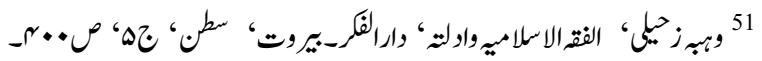$$
52
$$$$
53
$$$$
54
$$

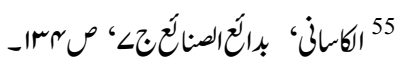

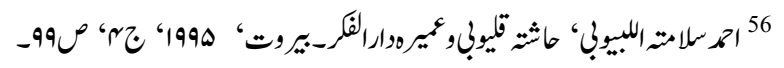

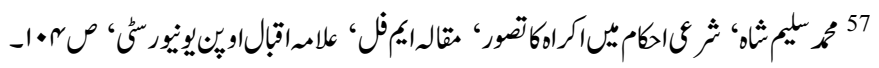

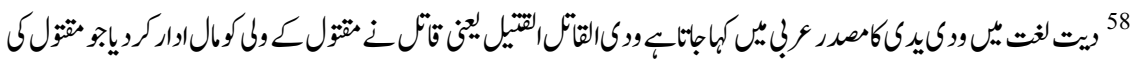

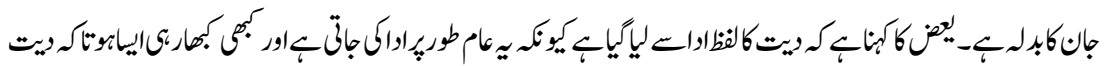




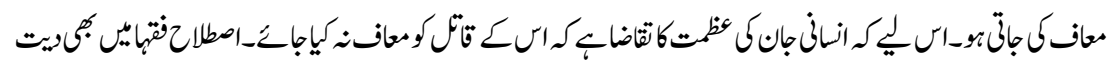

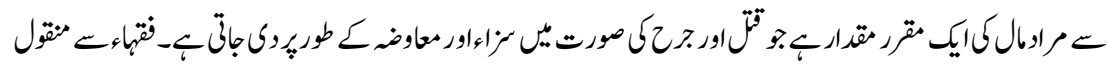

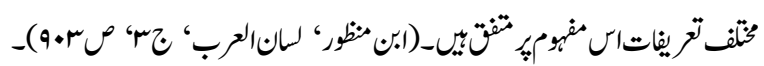
59

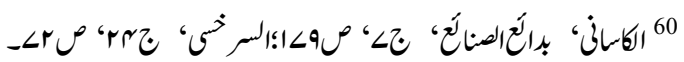

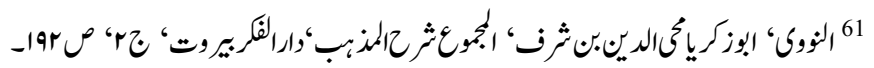

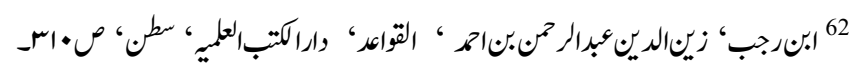

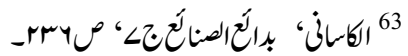

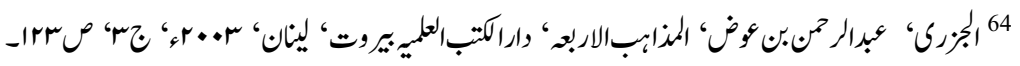

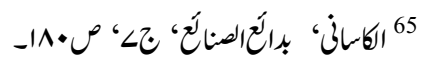
66 والهذكور 67

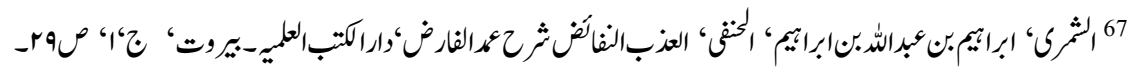

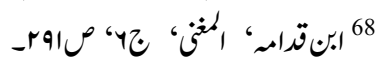

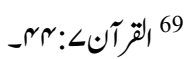
11

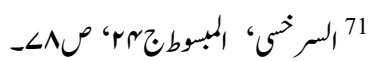

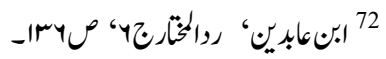

